\title{
9
}

\section{RNA biosynthesis}

Gene expression involves a sequential flow of information. In the first stage of this process, known as transcription, one strand of double-stranded DNA is copied into an RNA. In contrast to DNA replication, the genome is not copied in its entirety. Rather, defined units of genetic information are copied into RNA molecules which may function as messenger (mRNA), form a component of ribosomes (rRNA) or have an adapter function (tRNA). All three of these RNA products take part in the subsequent stage of gene expression, known as translation, in which mRNAs are used as coded messages for the synthesis of protein. Translation is the subject of chapter 12 .

\subsection{CONVENTIONS AND TERMS ASSOCIATED WITH RNA BIOSYNTHESIS}

RNA biosynthesis is called transcription. A transcription unit is a segment of DNA (gene or genes) that is transcribed (copied) into a single RNA molecule by the enzyme RNA polymerase. Associated with this segment of the genome are various nontranscribed DNA elements such as promoters, enhancers and operators that in- fluence the frequency with which any transcription unit is transcribed (they are to be fully described in forthcoming sections). These elements may include nucleotide sequences that are recognized by RNA polymerase or some other DNA-binding protein that modulates RNA synthesis. A given recognition sequence, or one like it, may thus be found associated with all the genes influenced by a particular protein. Such sequences are known as consensus sequences. Typically, they are not totally conserved but are a consensus from which any similar sequence deviates only marginally.

Associated with the controlled transcription of a gene, there may also be elements, such as regulator genes, that are independently transcribed and cause the formation of proteins that influence the frequency of transcription. Segments of DNA that influence the activity of genes with which they are contiguous are described as cisacting. This differentiates them from transacting elements that give rise to diffusible products that can act at many sites whether on the same or different chromosomes. Trans-acting elements are transcribed and translated into proteins called trans-acting factors or transcription factors. These 
influence transcription by interacting with promoters, enhancers and other cis-acting elements.

RNA is synthesized in a $5^{\prime} \rightarrow 3^{\prime}$ direction from the complementary strand of the DNA. However, when describing the nucleotide sequence of genes it is conventional to describe the coding strand as that having the same sequence as the RNA transcript (except that in the RNA, uridines replace thymidines). The point at which transcription starts is called the initiation site or start site. Sequences conventionally written to the left of the transcription unit are described as being $5^{\prime}$ to the start site. Such elements are also described as being upstream whereas those on the $3^{\prime}$-side of the start site are described as downstream. Individual nucleotides are numbered away from the start site and are given positive values when downstream and negative values when upstream. Thus, a nucleotide 20 base pairs before the start site is -20 and one 10 base pairs after the start site is at position +10 .

\subsection{TRANSCRIPTION IS BEST UNDERSTOOD IN PROKARYOTES}

\subsubsection{E. coli RNA polymerase}

The enzymes that catalyse the synthesis of RNA from a DNA template are known as DNA-dependent RNA polymerases. These enzymes require ribonucleoside triphosphates as substrates and transfer nucleoside monophosphates onto the $3^{\prime}-\mathrm{OH}$ terminus of the growing RNA chain. Polymerization is thus in a $5^{\prime} \rightarrow 3^{\prime}$ direction and produces an RNA chain the sequence of which is determined by Watson and Crick basepairing with the DNA template. RNA polymerase activity was first detected in rat liver nuclei by Weiss and Gladstone [1] but it is the bacterial enzymes, particularly that of $E$. coli, that are most fully characterized (reviewed in [2-4]). The complete E. coli enzyme or holoenzyme, of $M_{\mathrm{r}} 449068$, contains five polypeptide chains: two $\alpha$-chains of $M_{\mathrm{r}} 36512$; one $\beta$-chain of $M_{\mathrm{r}}$ 150619 ; one $\beta^{\prime}$-chain of $M_{\mathrm{r}} 155162$ and one $\sigma$-chain of $M_{\mathrm{r}} 70236$.

The $\beta$ and $\beta^{\prime}$-subunits each contain a $\mathrm{Zn}^{2+}$ ion [5] which is essential for catalytic activity. The enzyme requires all four ribonucleoside triphosphates and a divalent metal ion which in vivo is $\mathrm{Mg}^{2+}$ but in vitro can be $\mathrm{Mn}^{2+}$. When isolated, the enzyme normally consists of a mixture of the holoenzyme and the core enzyme from which the $\sigma$-subunit, commonly known as the sigma factor, is missing. The core enzyme is the catalytic component of the enzyme. It has a general ability to bind to DNA and, if the DNA is nicked, can catalyse the synthesis of RNA from the nicks. It is not, however, able to catalyse specific initiation. The addition of a sigma factor to the core enzyme reconstitutes a fully active holoenzyme [6] that now has reduced affinity for non-specific DNA sequences but a considerably increased affinity for specific recognition sites near the beginnings of the sequences to be transcribed. These sequences are known as promoters. Their nature and role in the initiation of transcription by RNA polymerase is further discussed in the following section. The transcription of most genes requires the predominant or primary sigma factor. In many species, however, there are alternative sigma factors that recognize the promoters of different sets of genes. Alternative RNA polymerase sigma factors are thus a means for the selective expression of specific genes and this is considered in section 10.3.1.

The function and mode of action of the subunits within the core enzyme are incompletely understood. Numerous studies 
employing inhibitors, affinity labelling, reconstitution and genetic methods [7-9] confirm that $\alpha, \beta$ and $\beta^{\prime}$ are all necessary components of the core enzyme. They also show that the $\beta^{\prime}$-subunit appears to be largely responsible for DNA binding. It is basic as would be expected of a protein with such a function and it binds the polyanion heparin that inhibits transcription in vitro. The $\beta$ subunit has been implicated in binding both the substrates and the products of catalysis and it contains at least a portion of the catalytic site for RNA synthesis. It is also the site of action of antibiotics such as the streptolydigins which inhibit RNA chain elongation and rifamycins which inhibit initiation by preventing the formation of the first phosphodiester bond.

There are approximately 7000 RNA polymerase molecules in an E. coli cell and, depending on the rate of growth, about 2000-5000 of these will be actively transcribing RNA at any given time. The RNA polymerases of other bacteria, as well as those of blue-green algae, are similar to those of $E$. coli and contain subunits that are homologous to the $\alpha, \beta, \beta^{\prime}$ and $\sigma$-chains. Indeed, in many though not all cases, the homology is such that reconstituted enzymes containing heterologous mixtures of subunits derived from different species are still catalytically active [3].

\subsubsection{Initiation of prokaryotic transcription}

The mechanism by which RNA polymerase initiates transcription has been most extensively studied with the enzyme from $E$. coli and has been shown to occur in three stages. First, the holoenzyme recognizes and binds to specific promoters. Second, this binding leads to the formation of the so-called 'open complex' in which a portion of the double helix is unwound. Finally, RNA synthesis is initiated (reviewed in [10]).

\section{(a) Binding of RNA polymerase to prokaryotic promoters}

The binding of RNA polymerase to transcriptional promoters appears to require an initial non-specific association with DNA. There are calculated to be $4 \times 10^{6}$ of these non-specific binding sites in the $E$. coli genome and the fact that this corresponds closely to the total number of base pairs $\left(4.5 \times 10^{6}\right)$ emphasizes the non-specific nature of the interaction. The non-specific binding constant of approximately $2 \times$ $10^{11} \mathrm{M}^{-1}$ is strong when set against the binding of many proteins to their ligands. Nevertheless, it is relatively weak compared with the binding to specific promoters and the DNA remains in the double-stranded (closed) form.

The precise role of non-specific binding and the mechanism by which the enzyme moves from them to specific promoters is not fully understood. Von Hippel and coworkers [11, 12] have shown that threedimensional diffusion processes are not fast enough to account for the transfer. Furthermore, they have reviewed evidence that suggests that non-specific binding is electrostatic and that, in this mode, facilitated transfer may occur by sliding along the DNA $[13,14]$ or by hopping [15] or a combination of both processes [16]. Heumann and coworkers [17, 18] have presented data favouring facilitated diffusion and have described the non-specific DNA as an 'antenna' along which RNA polymerase moves to the promoter. They reasoned that if such an effect occurred, occupancy of the promoter should be positively influenced by an increasing length of flanking sequence. Such an effect was demonstrated with downstream but not upstream sequences. 


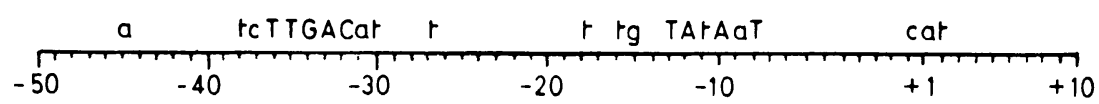

Fig. 9.1 Consensus sequence for the E. coli promoter.

Transfer from non-specific binding to a tight binding complex with a specific promoter depends on the presence of sigma factor. The binding constant for the association varies from $10^{12}$ to $10^{14} \mathrm{M}^{-1}$ and the strength of the complex, referred to as promoter strength, is strongly related to the efficiency with which the associated gene is transcribed.

E. coli RNA polymerase holoenzyme will protect promoter regions from nuclease attack. The length of the protected segment varies with the nuclease and digestion conditions used but it is clear that the enzyme binds asymmetrically to the start site of transcription such that it covers up to 50 nucleotides on the $5^{\prime}$-side of the gene and up to 20 nucleotides into the gene [13]. Within the $5^{\prime}$-side of this protected area, there are two segments, centred around nucleotides -10 and -35 , the sequences of which are strongly conserved. It is these segments that are the promoters to which the holoenzyme binds. The -10 sequence, often known as the Pribnow Box, has the consensus sequence TATAAT and the -35 region has a consensus sequence TTGACA $[19,20]$. It should be emphasized that not all promoters have these sequences. However, any given promoter will vary from the consensus at no more than a few positions and this variation is more likely to occur in some nucleotides than in others. Thus, in a compilation of 112 well-defined E. coli promoter regions [21], a consensus sequence for the region -50 to +10 was derived. This is illustrated in Fig. 9.1, where upper case letters indicate strongly conserved nucleotides, lower case letters represent weakly conserved nucleotides and no letters are inserted where there is no evidence for conservation. The importance of the consensus sequences has also been investigated in promoter mutants $[21,22]$ which are described as down or up mutants depending on whether they decrease or increase transcription from the promoter. In an analysis of $98 E$. coli mutants, nearly all followed a general rule that down mutants showed decreased homology with the consensus sequence whereas up mutants had increased homology [22]. The length of DNA between the -10 and -35 regions is also fairly stable; 100 of the 112 promoter sequences compiled by Hawley and McClure [21] had $17 \pm 1$ intervening nucleotides, however sequences ranging from 15 to 20 nucleotides are known. Similarly the distance between the -10 region and the transcription start site can vary from 5 to 9 nucleotides.

An overall picture of $E$. coli promoters is thus of fairly tightly constrained sequence and spatially defined elements but nevertheless with a substantial degree of variability. Many promoters are in fact weak; their function relies on and is controlled by other proteins that recognize regulatory elements and assist initiation (These controlling factors are considered in chapter 10.) Notwithstanding this, there are still problems. First, it is not clear that there is sufficient information in what is understood of promoter elements to define their unambiguous recognition by RNA polymerase. Second, there is little correlation between initial promoter recognition (rate of complex formation) and promoter strength defined 


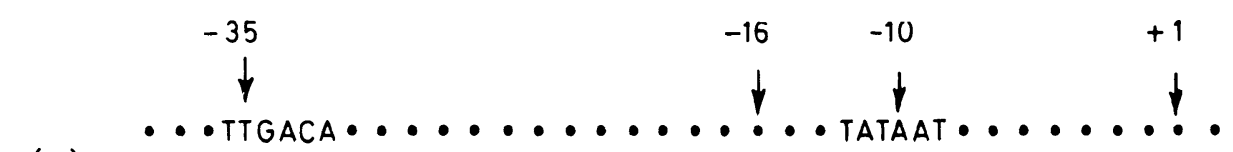

(a)

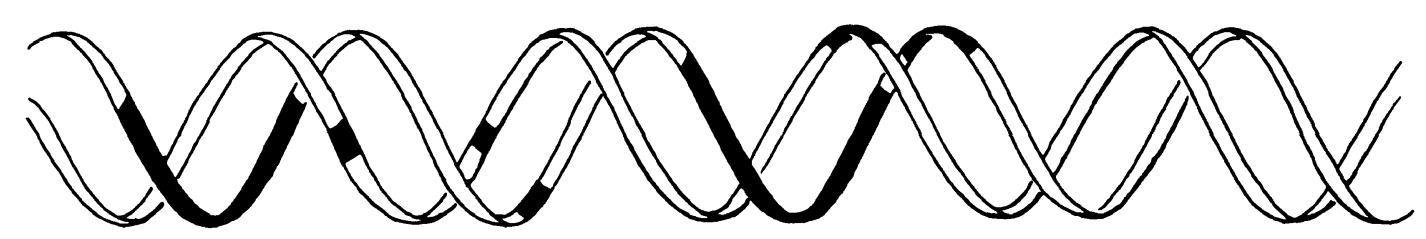

(b)

Fig. 9.2 Contact points for $E$. coli RNA polymerase on the promoter of the $\beta$-galactosidase gene. The sequence of the promoter coding strand (a) is aligned with the distribution of contact points (darkened areas) on one face of the DNA double helix (b).

as rate of RNA synthesis [23]. O'Neil [24], in an analysis of 52 well-characterized promoters, found that on average they conserved only 3.9 bases in the -35 consensus sequence and 4.2 bases in the -10 consensus sequence. This level of degeneracy could lead on average to promoter recognition every 200 base pairs of DNA; obviously with many false positives. Clearly, additional information must specify an RNA polymerase recognition site.

Some further information comes from the analysis of contact points between RNA polymerase and its promoter. Such experiments are performed by examining the extent to which the polymerase can protect specific nucleotides from base-modifying reagents. Alternatively, mutations and base-specific reagents can be tested for their effect on enzyme binding. Contact points are heavily concentrated in the -35 and -10 consensus regions of the DNA and are also clustered in the -16 area [20]. In all three areas, the contact nucleotides are not always those that are most strongly conserved (Fig. 9.2) so it would appear that features additional to base sequence, such as three-dimensional structure and hydrogen-bond pattern [12], may be important in enzyme recognition. That threedimensional structure must be important is indicated by the finding that the length of the DNA segment between the -10 and -35 regions has considerable influence on promoter strength. In the B form of DNA, the $-35,-10$ and -16 regions all lie on the face to which RNA polymerase binds; a change in the length of the intervening segment would skew this arrangement [25] which might also be influenced by supercoiling [26]. One recent suggestion is that there are three classes of promoter depending on whether there are 16,17 or 18 nucleotides between the -10 and -35 regions [24].

Experiments with mutant sigma factors and with mutant promoters demonstrate that the factor recognizes both the -10 and the -35 regions on the promoter ([27] and references therein). Two out of four highly conserved regions of the polypeptide are involved in the recognition.

The promoters of bacteriophage that rely on the RNA polymerase of their host compete very effectively for the enzyme. It is perhaps surprising, therefore, that the 
consensus sequence of 29 bacteriophage T4 promoters differs significantly from that of $E$. coli [28]. The difference raises the possibility that additional proteins are involved in their recognition. Variant prokaryotic RNA polymerase promoters associated with the expression of complex gene sets are discussed in section 10.3.1.

(b) Formation of an open promoter complex and the initiation of RNA synthesis

With the tight binding of RNA polymerase to a promoter site, there is a rapid transition to the so-called open-complex in which the DNA is partially unwound (Fig. 9.3). Unwound regions of DNA are accessible to base-modifying reagents. Siebenlist et al. [20] exploited this and used dimethyl sulphate to methylate the $\mathrm{N} 1$ and $\mathrm{N} 3$ positions of adenines and cytosines, respectively, in the unwound segments of the open complex. They showed that a $12 \mathrm{bp}$ region of the promoter is unwound and stretches from the middle of the -10 region to just beyond the RNA start site (specifically from -9 to $+3)$. The fact that this region overlaps with a contact point between one strand of the DNA and sigma factor [27] indicates that the essential role of this subunit in correct initiation may be associated with the formation of open complexes. Buc and colleagues [29-32] have investigated both the opening and the associated unwinding of strong and weak promoters. They find that although the kinetics of opening are different, both open to the same extent, i.e. about $12 \mathrm{bp}$. They have further investigated the role of supercoiling in the process and have suggested that initially the DNA is wrapped around the polymerase in a nucleosome-like form [32]. In at least some promoters, the open complex is then believed to form via an intermediate step:

$$
\begin{gathered}
\mathrm{R}+\mathrm{P} \stackrel{\text { fast }}{\longrightarrow} \mathrm{RP}_{\mathrm{c}} \stackrel{\text { rate-limiting step }}{\longrightarrow} \mathrm{RP}_{\mathrm{i}} \\
\stackrel{\text { major induced-fit }}{\longrightarrow} \mathrm{RP}_{0}
\end{gathered}
$$

$\mathrm{R}$ is RNA polymerase and $\mathrm{P}$ is the promoter. $\mathrm{RP}_{\mathrm{c}}$ is the closed enzyme promoter complex in which the DNA is still double-stranded and the -10 and -35 regions are not fully registered with the enzyme. $\mathrm{RP}_{\mathrm{i}}$ is envisaged as an intermediate stage in which the DNA is still double-stranded but the -10 and -35 regions are in register and the enzyme is strictly positioned with respect to the DNA backbone. During the transition between $\mathrm{RP}_{\mathrm{c}}$ and $\mathrm{RP}_{\mathrm{i}}$, the DNA is topologically unwound and the unwinding (untwisting or negative writhing) is converted into strand separation in the final step; the formation of the open complex, $\mathrm{RP}_{0}$.

Transcription in prokaryotes is most commonly initiated with a purine nucleotide at a site 6 or $7 \mathrm{bp}$ downstream from the -10 region. Of 88 promoter start sites examined by Hawley and McClure [21], A and G occurred at position +1 of the coding strand 45 and 37 times, respectively, and pyrimidines occurred in only six sequences. They also demonstrated that pyrimidines were preferred at positions -1 and +2 with CAT as the overall consensus sequence for the triplet $-1,+1,+2$ (Fig. 9.1). Thus, a consensus transcript would begin pppApU. The binding of the initiation nucleotide to RNA polymerase is an order of magnitude stronger than that of succeeding nucleotides and it has been suggested that it occupies a separate initiating site on the enzyme [33].

At an early point in the incorporation of nucleoside phosphates into new transcripts, two further changes occur in the initiation complex. In the first of these, the open complex is transformed into a ternary complex which is much more resistant to dissociation by high salt concentrations, is resistant to inhibition by rifampicin and in which RNA 


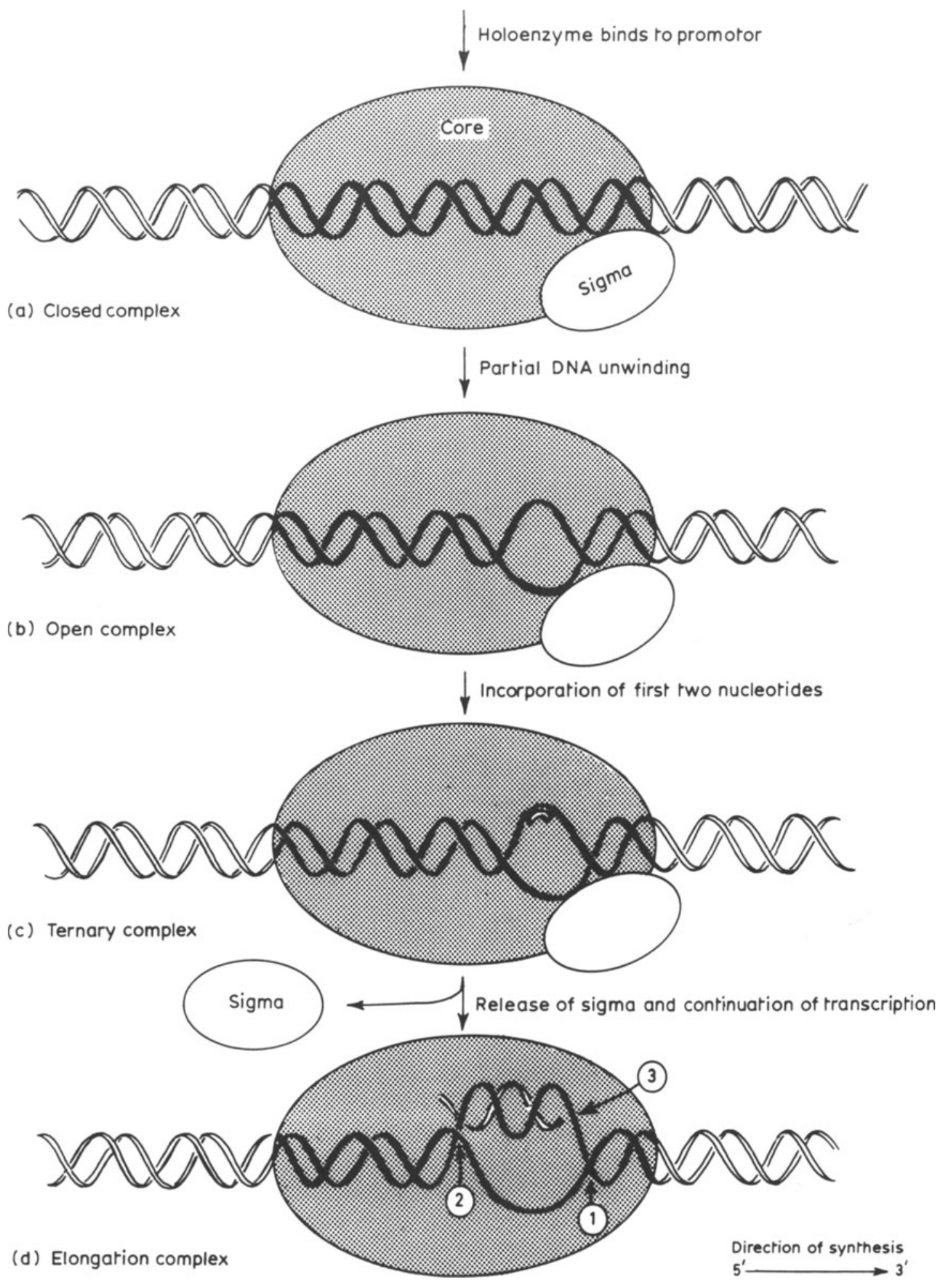

Fig. 9.3 Diagrammatic representation of the stages in the initiation of transcription. On the elongation complex (d) 1,2 and 3 represent the active centres for the removal of positive supercoiling, the removal of negative supercoiling and elongation, respectively. 


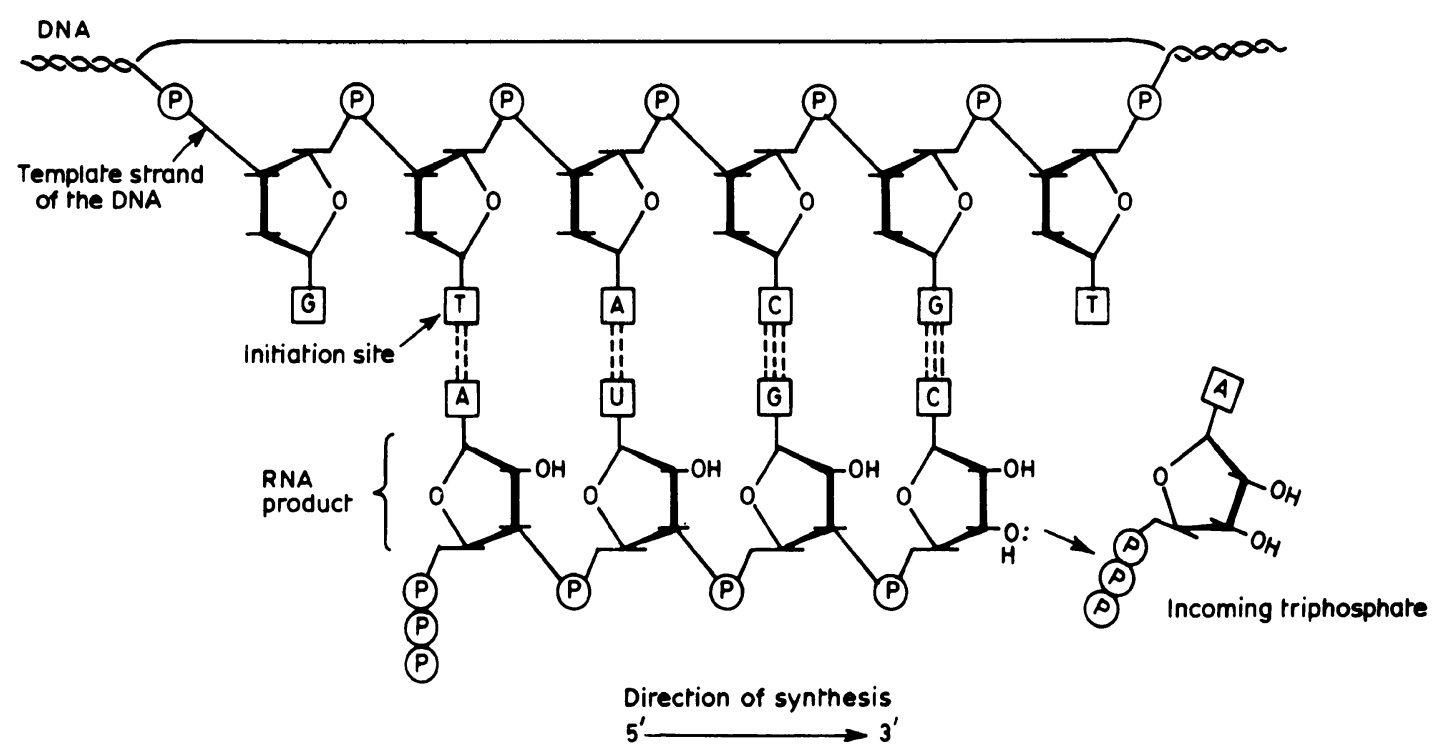

Fig. 9.4 A diagrammatic representation of the biosynthesis of RNA from the strand of the DNA that acts as a template.

polymerase is more resistant to denaturation and to proteolytic enzymes. DNase footprinting (section A.9.2), photoaffinity labelling and rapid kinetics have been used to study the structure of this ternary complex [34-36]. They show that RNA polymerase remains more or less fixed on the promoter as the first eight nucleotides are polymerized into RNA. At this time, sigma factor is still attached to the enzyme and the promoter shows increased sensitivity to DNase at position -25 , perhaps indicating bending of the DNA in this region [34]. Sigma factor is released after the polymerization of 10 nucleotides [34] and the release is apparently dependent on and driven by the nucleotide sequence of the promoter [35]. Only after the incorporation of 10 nucleotides is there movement of the enzyme from the promoter and a commitment to elongation [34]. The released subunit is recycled and continued elongation of the transcript is catalysed by the core enzyme (Fig. 9.3).

\subsubsection{Elongation of prokaryotic transcripts}

Elongation proceeds by the successive addition of ribonucleoside monophosphates from substrate triphosphates on to the $3^{\prime}-\mathrm{OH}$ terminus of the growing RNA chain (Fig. 9.4). The nature of the incoming nucleotide is governed by Watson-Crick base-pairing rules and bond formation is accompanied by the release of pyrophosphate. The reaction can thus be represented as:

$$
\mathrm{pppXpY} \stackrel{n Z \mathrm{ZTP}}{\longrightarrow} \mathrm{pppXpY}(\mathrm{pZ})_{n}+n \mathrm{PP}_{\mathrm{i}}
$$

$\mathrm{X}, \mathrm{Y}$ and $\mathrm{Z}$ can be any of the four ribonucleotides although evidence has already been presented for the preferred insertion of purines as the $5^{\prime}$-nucleotide. The elongation complex is diagrammatically illustrated in Fig. 9.3(d).

There is a mechanical problem posed by the progress of RNA polymerase that is best 
conceptualized by a simple model. Take a double stand of fixed cord, such as the double string employed to draw a blind. If this is rotated repeatedly clockwise, a double helix is produced that can serve as our model of DNA. Now insert a pencil through the helix and move it away from you between the strings. You have, in effect, a mechanistic model of RNA polymerase moving along the DNA helix and, as you move the pencil, the string will overwind in front of the pencil and underwind behind. This is exactly what is considered to happen in transcription. The DNA will become positively supercoiled in front of RNA polymerase and negatively supercoiled behind it [37]. If we now continue our experiment, we rapidly reach a point at which we cannot push the pencil any further; there is too much resistance from the overwound string and it cannot be overwound anymore. In a cell, such overwinding must be released. One way to do this would be to allow the DNA and transcribing machinery to rotate around each other. This immediately appears unlikely. The enormously long filament of DNA could hardly rotate and the concept of the growing nascent RNA chain rotating around the DNA is almost as bizarre. The solution proposed by Liu and Wang [37], in their twin-supercoiled-domain model, was that waves of supercoiling generated by the transcribing polymerase would be released enzymically. DNA gyrase (topoisomerase II) would remove the positive supercoiling ahead of the RNA polymerase and DNA topoisomerase I would remove negative supercoiling behind it. Wang and coworkers $[38,39]$ have since used inhibitors of the different topoisomerases to confirm the existence of waves of supercoiling in vivo. Studies in vitro [40] have also provided supporting data.

RNA polymerases from a wide variety of bacteria catalyse the synthesis of RNA from a natural template at 12-19 nucleotides per second [41]. This is slower than the theoretical rate of up to 60 nucleotides per second because transcription from natural templates is not uniform. Many groups have shown that elongation is a discontinuous process in that there are pause sites along the DNA at which RNA polymerase slows or stops. Elongation is rapid between these sites (e.g. [42]). Pausing occurs at GC-rich regions and at points 16-20 nucleotides downstream of regions of dyad symmetry. At these latter regions the delay is associated with the formation, by the nascent RNA, of stem-loop structures either because it base pairs with itself or with the coding strand of the DNA [43, 44]. Pausing is a necessary preliminary to termination (section 9.2.4) and premature termination can occur at internal pausing sites (section 10.2). Viral RNA polymerases are apparently not delayed by the DNA of their hosts and have been reported to elongate at up to 200 nucleotides per second [45].

A number of inhibitors have proved useful for the study of elongation [41-45]. The antibiotics rifampicin and streptovaricin bind to the $\beta$ subunit and block initiation whereas streptolydigin also binds to the $\beta$ subunit but interferes with the elongation steps. Another agent which prevents elongation is actinomycin D. However, it does so, not by binding to the enzyme, but by complexing with deoxyguanosine residues in the DNA template and thus preventing movement of the core enzyme along the template (section 7.2.3).

\subsubsection{Termination of prokaryotic transcripts}

Three events are required when the transcription of a gene is terminated; elongation ceases, the transcript is released and RNA 
polymerase is released. Studies with prokaryotes have demonstrated that these events occur by at least two mechanisms that are known as factor-independent termination and factor-dependent termination. Both of these have been the subject of reviews [29, 46-48]. Before discussing each in turn it should be stressed that the precise identification of termination sites is not easy. The $5^{\prime}$-end of a prokaryotic transcript can be unambiguously identified by its triphosphate group. No such marker defines the terminus of transcription and an observed $3^{\prime}$-end may be the result of posttranscriptional cleavage.

Termination has largely been studied in vitro using methods that involve the synthesis, by purified RNA polymerase, of specific transcripts from bacteriophage or from defined bacterial genes. Commonly used systems include the bacterial trp operon (genes encoding the enzymes that synthesize tryptophan), the DNA coliphages T7, T3, $\phi X 174$ and bacteriophage lambda. Termination occurs at defined sites in these systems and, in a number of them, concern that the sites might be artifacts of in vitro incubation conditions has been dispelled by confirmation of their use in vivo.

\section{(a) Factor-independent termination}

Sites on the DNA at which independent termination occurs have a characteristic structure that comprises a GC-rich inverted repeat followed, on the template strand, by a run of adenylate residues. The former of these regions results in the formation of GC-rich regions in the transcript, which are able to base-pair into a 'hairpin' or stemloop structure (Fig. 9.5). Such loops, which typically contain seven to ten G:C base pairs, have been shown to cause RNA polymerase to pause [49]. Mutations that lengthen the region of dyad symmetry, over a minimum of $6 \mathrm{bp}$, strengthen the efficiency of termination as does the incorporation into the transcript of nucleotide analogues, such as bromo- or iodo-CMP, that stabilize $\mathrm{G}: \mathrm{C}$ pairs. Conversely, weakening of G:C pairs, such as occurs when inosine is substituted for guanosine, decreases termination efficiency [46].

Shortly after the GC-rich region, a run of four to eight adenylates in the template will dictate that a string of uridylate residues are transcribed into the nascent RNA. Decreasing the number of these residues has been shown to reduce the efficiency of termination [50] and it appears that the importance of the sequence resides in the very unstable nature of the rU:dA hybrid [51]. Thus three features, the disruption of the RNA:DNA hybrid caused by $\mathrm{G}: \mathrm{C}$ base-pairing, the pausing of RNA polymerase and instability of the rU:dA region, all combine to facilitate the release of the transcript from the template. O'Hare and Hayward [52], working with a termination site, $\mathrm{T} 1$, of coliphage $\mathrm{T} 7$, found that in vitro recognition of the stop signal and release of RNA occurred with a $t_{1 / 2}$ of $3 \mathrm{~min}$ whereas release of RNA polymerase took $12 \mathrm{~min}$. However, more recent analyses indicate that the enzyme is released within $13 \mathrm{~s}$ of the cessation of elongation [53]. Platt [271] has suggested that RNA polymerase undergoes a conformational change to a termination complex at some time in this process and the concept is supported by the isolation of polymerase mutants that are modified in termination efficiency. Arndt and Chamberlin [54] have suggested that the RNA hairpins bring about this conformational change by converting the ternary elongation complex into what they call a 'release mode'.

Some recent data $[55,56]$ suggest that the above picture of factor-independent termination may be somewhat simplistic. It 


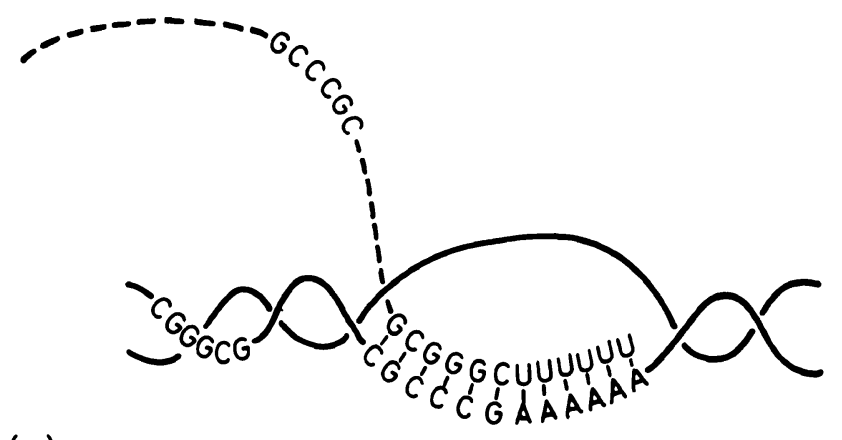

(a)

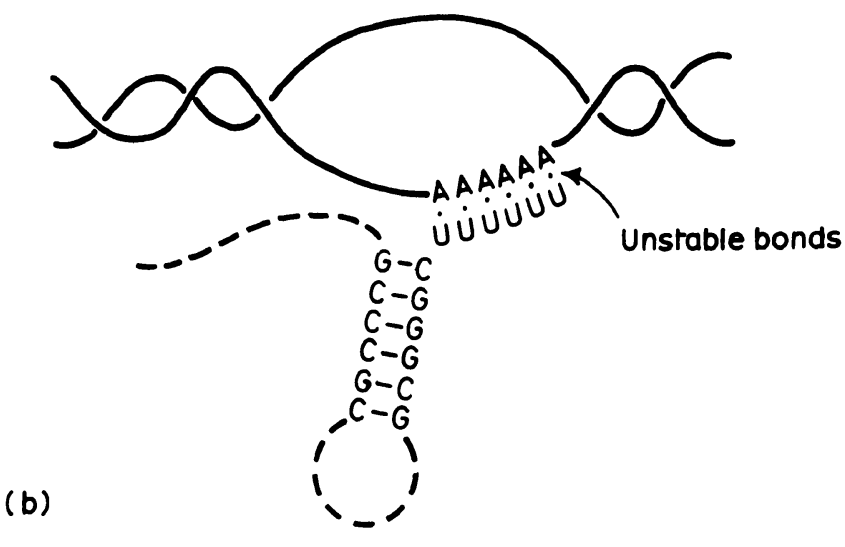

Fig. 9.5 Independent termination. RNA polymerase is omitted from the diagram for reasons of clarity (adapted from Platt [271]). (a) point at which elongation stops. (b) formation of hairpin followed by termination.

was demonstrated that sequences associated with the promoter can have a profound influence on termination but the way in which this occurs is totally unknown.

\section{(b) Factor-dependent termination}

Roberts [57] discovered a protein, which he called rho $(\rho)$, that when added to an $E$. coli transcription system in vitro causes the generation of transcripts with discrete $3^{\prime}$-ends. The protein is basic in character and in solution consists of six identical, 419 amino acid subunits arranged in a ring structure. It recognizes and binds to the nascent RNA transcript and the RNAbinding domain is in the first 151 amino acids of the subunit [58]. It binds to $13 \pm 1$ nucleotides per monomer and $78 \pm 6$ nucleotides per hexamer [59] such that the polynucleotide appears to be wrapped around or condensed within the protein oligomer [60]. The protein also exhibits RNA-dependent ATPase activity that is located in the carboxyl two thirds of the polypeptide [61] and is required for the helicase activity that brings about the unwinding of RNA:DNA hybrids [62-64]. 
As with independent termination, the activity of rho requires RNA polymerase to pause in its elongation [65]. Rho-dependent sites (rut sites) are cytosine-rich and guanosine-poor [260] but they do not have the degree of sequence conservation associated with rho-independent sites. Although many can be drawn as stem-loop structures, the base-pairing tends to be relatively unstable and largely involves A:U basepairing. Indeed, a considerable body of evidence has accumulated showing that rhodependent termination is enhanced by decreased secondary structure in the RNA transcript [65] and that rho binds to nascent mRNA that is relatively free of secondary structure [66]. Models for rho-dependent termination $[46,50,67,68]$ propose that the factor first binds to nascent RNA that lacks secondary structure. It may then move along the transcript until it finds a paused RNA polymerase and this movement could require the hydrolysis of nucleoside triphosphate [46]. Alternatively, the hydrolysis of NTP may result from a conformational change in rho brought about by the interaction of the nucleotide with the ternary complex. This in turn could cause the release of the nascent RNA chain ([62] and references therein).

It seems likely that there are a number of factors that bring about termination in prokaryotes. Nus A protein, which is considered in chapter 10 under the control of termination (section 10.2.2), is a termination factor that, in bacteriophage lambda, interacts with an anti-termination factor N. Antitermination is a process whereby RNA polymerase is rendered insensitive to some termination mechanisms. The best-known systems in which it has been studied are; the regulation of gene expression in bacteriophage lambda (section 10.2.2); the attenuation of amino acid biosynthetic operons (section 10.2.1) and antitermination of $E$. coli rRNA synthesis which appears to share many similarities with the bacteriophage lambda system ([69] and references therein).

\subsection{EUKARYOTES HAVE THREE DIFFERENT NUCLEAR RNA POLYMERASES}

Transcription in eukaryotic nuclei is performed by three separate enzymes [70-74]. RNA polymerase I is located in the nucleoli, transcribes the genes for rRNA and is responsible for $50-70 \%$ of total RNA transcription. RNA polymerase II occurs in the nucleoplasm and synthesizes mRNA precursors and most of the U-series of small nuclear RNAs (snRNAs). It accounts for $20-40 \%$ of total RNA transcription. RNA polymerase III is also located in the nucleoplasm and transcribes a series of small RNAs. These include RNA species required for protein synthesis (tRNA and 5S RNA), one of the snRNAs required for mRNA processing (U6 snRNA), a small RNA required for protein transport (7SL RNA), RNAs required for the regulation of viral gene expression (adenovirus VA RNA and Epstein Barr Virus EBER RNA) and other small RNA species of unknown function, such as 7SK RNA. RNA polymerase III synthesizes approximately $10 \%$ of total transcribed RNA.

All three enzymes catalyse RNA synthesis on a DNA template as previously described for the $E$. coli enzyme and they require a divalent metal ion which can be $\mathrm{Mg}^{2+}$ or $\mathrm{Mn}^{2+}$. When assayed in vitro, polymerase II is much more active with $\mathrm{Mn}^{2+}$ and polymerase III is slightly so. However, concentrations of $\mathrm{Mn}^{2+}$ in vivo are low and there is evidence that the use of $\mathrm{Mn}^{2+}$ in vitro may alter the binding properties of the enzyme [75]. In the analysis of enzyme 
activity, use is also made of their differing sensitivity to the fungal amatoxins $(\alpha-, \beta$ and $\gamma$-amanitin, amanin and amanullin) of which the most commonly used is $\alpha$ amanitin. RNA polymerase II is inhibited by $\alpha$-amanitin at $50 \mathrm{ng} / \mathrm{ml}$. RNA polymerase III is much less sensitive but is inhibited at concentrations of $5 \mu \mathrm{g} / \mathrm{ml}$ whereas RNA polymerase II is insensitive. De Mercoyrol [76] has demonstrated that $\alpha$-amanitin does not block the formation of the first phosphodiester bond but inhibits the catalytic accumulation of trinucleotide, perhaps because it blocks an isomerization step required for translocation after phosphodiester bond formation. As with prokaryotic RNA polymerase, all three eukaryotic enzymes contain bound zinc, probably associated with a conserved amino acid sequence in the largest subunits [77].

Sedimentation analyses show that all three enzymes are very large with $M_{\mathrm{r}}$ values of 500000-600000 and they contain up to 15 subunits. Tabulation of the components of the three polymerases from various sources [70] reveals substantial interspecies variation in the $M_{\mathrm{r}}$ and numbers of the subunits. Thus polymerase III has been reported to have from 9 to 15 subunits depending on the species from which it is isolated. In general terms, however, each enzyme possesses two non-identical, large subunits of $M_{\mathrm{r}} 120000-220000$ and up to 13 smaller subunits which, with the exception of an 80000-90000 subunit in polymerase III, have $M_{\mathrm{r}}$ of less than 50000 . Lewis and Burgess [78] have discussed the difficulty of ascertaining the precise number of subunits in the active enzymes. Some subunits may only be present in the purified enzyme at a molar ratio of less than one molecule per enzyme molecule. Several explanations are possible for such a lack of stoichiometry. The polypeptide concerned could be a contaminant or it could be a genuine subunit that is differentially lost during enzyme purification. If a subunit functioned as a factor, this could also explain low abundance. A factor like sigma in the $E$. coli enzyme, that is only required at certain points in the transcription cycle, would not necessarily occur in stoichiometric amounts on the purified enzyme.

Since it is not yet possible to reconstitute active enzyme from its subunits, the functional significance of any component is hard to ascertain but considerable progress is being made with the recently developed method of epitope tagging. In the first stage of this technique, a gene encoding a polymerase subunit is modified so that, during protein synthesis, an extra string of amino acids is inserted on the end of the polypeptide. The extra amino acids are chosen so as to minimize disruption of the protein and, most importantly, so that they are recognized by a well-characterized monoclonal antibody. The enzyme can then be purified by gentle immunoaffinity methods and the subunit composition compared with that derived after more traditional purification techniques.

Perhaps the most studied enzyme is RNA polymerase II which has been purified to near homogeneity from more than 20 different species. That of the yeast, Saccharomyces cerevisiae, has ten subunits (RPB1-RPB10) whether purified by conventional techniques or by immunoprecipitation with a monoclonal antibody against epitope-tagged subunit 3 [79]. Each subunit is encoded by a single copy gene but the enzyme appears to be composed of one polypeptide of each of RPB1, 2, 6, 8 and 10 , two copies of each of RPB3, 5 and 9, and less than stoichiometric amounts of subunits RPB4 and 7.

The two largest subunits of the enzyme contain extensive regions of homology with the $\beta$ and $\beta^{\prime}$-subunits of $E$. coli RNA poly- 
merase [80] and are related in size and sequence to the large subunits of RNA polymerases I and III [73]. The largest subunit of $220 \mathrm{kDa}$ is the largest of any of the RNA polymerases and experiments involving cross-linking, together with susceptibility to antibodies and proteases, indicate that it is involved in binding to the DNA template [71]. It contains, in addition to the regions of homology with other enzymes, a carboxy-terminal domain (CTD) that forms an extension or tail to the core enzyme and consists of tandem repeats of a seven amino acid sequence: Tyr-Ser-ProThr-Ser-Pro-Ser (reviewed in [81]). The tandem repeats are common to all known RNA polymerase II enzymes but the number of repeats varies from 17 in the malarial parasite to 52 in mammals. The extension is essential for enzyme function and may be unphosphorylated (RNA polymerase IIA) or extensively phosphorylated (RNA polymerase IIO). Phosphorylation causes a conformational change in the carboxyl domain [261] and recent data indicate that polymerase IIA forms the initiation complex but that phosphorylation of the $C$-terminal domain occurs before the initiation of transcription [82]. There is also evidence that transcription factors could interact with the domain [83].

The next largest subunit of RNA polymerase II, RPB2, appears to participate in substrate binding [85] and phosphodiester bond formation, thus showing functional homology with the $\beta$ subunit of bacterial enzymes. The third largest subunit is also an essential component of the transcription apparatus [84], may be the equivalent of subunit RPC5 that is common to RNA polymerases I and III, and is probably the functional homologue of prokaryotic sigma factor [84]. At least three other subunits, RPB5, RPB6 and RPB8, are immunologically and biochemically indistinguishable in RNA polymerases I, II and III [86]. It would thus appear that many of the enzymic components are substantially preserved between the three eukaryotic enzymes and indeed exhibit considerable similarities with prokaryotic RNA polymerase.

\subsection{THE INITIATION OF EUKARYOTIC TRANSCRIPTION}

The study of eukaryotic RNA polymerase activity has been much enhanced by the development of systems in which the enzymes correctly transcribe specific genes in vitro. The first of these was a transcription system for polymerase III [87] and led to the use of extracts of Xenopus oocytes as a major system to support transcription by this enzyme [88, 89]. Similar systems, employing extracts of tissue culture cells, were also described for the transcription of cloned eukaryotic genes and of viral genes by both polymerases II and III $[90,91]$. The last to be developed was a cell-free extract that correctly initiated the transcription of pre-rRNA from cloned rDNA [92]. Such polymerase I-dependent systems are species-specific [93].

Transcription is also studied by the microinjection of cloned eukaryotic genes into Xenopus oocytes [94], by the stable introduction of genes into mammalian cells in culture [95] and by the insertion of cellular genes into an SV40 viral vector [96] or a plasmid containing the SV40 or other viral replication origins [97].

The use of such systems has shown that RNA synthesis by eukaryotic polymerases has much in common with that catalysed by the prokaryotic enzyme. Since there are three nuclear enzymes, however, one may expect differences between the three in promoter recognition as well as termination and control of transcription. 


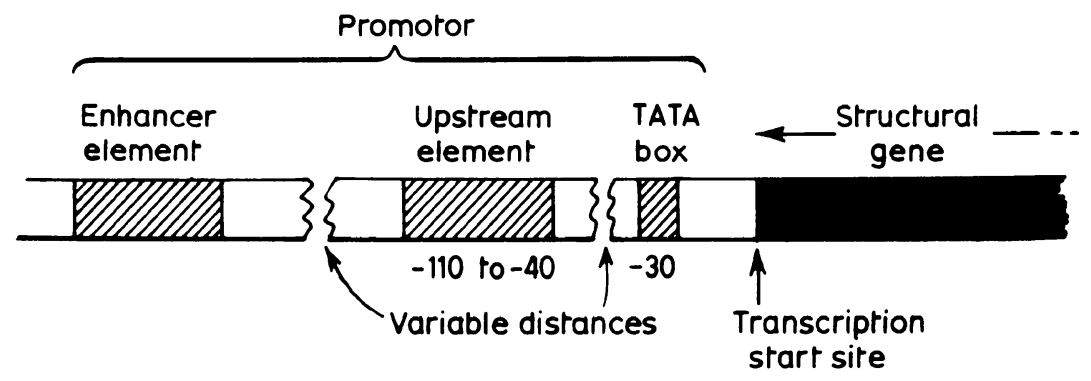

Fig. 9.6 A diagram of the promoter region for RNA polymerase II.

\subsubsection{Initiation by RNA polymerase II}

The promoter for RNA polymerase II consists of a number of sequence elements required for accurate and efficient initiation of transcription (reviewed in [71]). Two of these show similarities with the conserved sequences of prokaryotes. The first conserved element, identified when the 5'regions of eukaryotic gene sequences were compared, was originally named the Goldberg/Hogness box after its discoverers [98]. It is now usually called the TATA box and is an AT-rich region with the consensus sequence:

$$
5^{\prime} \operatorname{TATA}_{\mathrm{T}}^{\mathrm{A}} \mathrm{A}_{\mathrm{T}}^{\mathrm{A}} 3^{\prime}
$$

It occurs approximately $30 \mathrm{bp}$ upstream from the transcriptional start site in most eukaryotes (Fig. 9.6) but 60-120 nucleotides upstream of the start site of yeast genes. It has been called the selector sequence and its function is to fix the location of the start site. Mutations in the consensus sequence can profoundly affect correct initiation. Conversely, nucleotide deletions to the transcription start site region result in initiation at a new site, still approximately $30 \mathrm{bp}$ downstream from the TATA box. Although this element is obviously very similar to the prokaryotic Pribnow box two differences are thus immediately apparent. First, the Pribnow box is $10 \mathrm{bp}$ (one DNA helical turn) from the start site of prokaryotic transcription. Second, there is a degree of sequence conservation in the prokaryotic start site but much greater variability in eukaryotes. Transcriptional analysis and S1 nuclease mapping have shown that a functional TATA box precedes most genes transcribed by RNA polymerase II. There are, however, genes, such as the late SV40 genes and U1 snRNA genes, that contain equivalent sequences that can at best only be described as TATA-like [99, 100]. They may form another class of promoter. Other genes that lack TATA boxes are the so-called housekeeping genes that encode constitutively expressed proteins that are continuously expressed but at a low level [101]. The genes have a CG-rich promoter that is discussed in section 10.6.2 and their transcripts have multiple 5 '-ends.

The second element in the RNA polymerase II promoter is the so-called upstream promoter element (UPE). It occurs in most protein-encoding genes and consists of one or more 8-12 nucleotide segments located a variable distance $(-40$ to -110$)$ upstream of the transcription start site (Fig. 9.6). Whereas the function of the TATA box is to ensure accurate initiation of transcription, the UPE increases the rate of transcription. One common variant of the UPE is the so-called CAAT or CCAAT box which has the consensus sequence: 


\section{$5^{\prime} \mathrm{GG}_{\mathrm{C}}^{\mathrm{T}} \mathrm{CAA} \mathrm{A}_{\mathrm{A}}^{\mathrm{T}} \mathrm{CT} 3^{\prime}$}

and occurs 70-90 bp upstream from the start site. A further variant is a GC-rich sequence (GC box) with the consensus:

\section{5' CCGCCC 3'}

or its complement:

\section{5' GGGCGG 3'}

which can occur in one or more copies $[102,103]$ and may be present in addition to a CAAT box as the so-called -100 element [104].

More complex regulation of transcription is provided by enhancer elements (Fig. 9.6). These are short stretches of nucleotides which act in cis to increase the transcription of nearby genes. They function relatively independently of position, orientation and distance. Some show narrow tissue and temporal specificity whereas others permit expression in many cell types.

Although presented above as three separate elements, the distinction between promoters, upstream elements and enhancers is blurred. They share many properties and often overlap, with the same consensus sequence serving as both promoter and enhancer. It will be convenient here, however, to discuss the role of TATA boxes and UPEs in the initiation of transcription while leaving enhancers and their role in the regulation of transcription to be considered under the control of gene expression (chapter 10).

Most, probably all, of the above sequence elements are targets for proteins. Indeed, eukaryotic RNA polymerases are unable to recognize promoters without the aid of proteins. Often called transcription factors, these proteins are frequently present at very low concentrations but they are initially detected in cellular fractions required for transcription in vitro from a DNA template containing a promoter sequence. They are then often identified by DNA footprinting and gel retardation assays (section A.9.2) and, in an increasing number of cases, they have been substantially purified by recognition-site affinity chromatography. In some cases, their genes have been cloned.

The use of soluble, cell-free systems to transcribe a DNA template with a minimal TATA box promoter led to the identification of sets of transcription initiation factors from various species and cell types. Inevitably, this resulted in multiple names and acronyms that without doubt describe the same or closely related proteins. Table 9.1 presents the most generally accepted names that will be used for the remainder of this discussion and also lists the probable functional equivalents that have been described from other systems.

The pivotal factor in the recognition of the TATA box is most commonly called TFIID (transcription factor D for RNA polymerase II). It binds the TATA box independently, without the involvement of other factors or RNA polymerase ([111] and references therein). It is also apparently the factor that recognizes and binds to promoters with little TATA box homology [112]. TFIID has been described as a commitment factor as its binding is a prerequisite for the formation of the basal transcription apparatus (Fig. 9.7) that includes RNA polymerase II and several more factors: TFIIA, TFIIB, TFIIE (reviewed in [113]). Of these, TFIIA stimulates and facilitates the binding of TFIID but is not always required. TFIIE is multicomponent and has been separated into TFIIE and TFIIF of which the latter consists of two polypeptides of $30 \mathrm{kDa}$ and $78 \mathrm{kDa}$. Impure TFIIF has helicase activity [109] but this is not present in pure FC which is probably the same protein [108]. More recently, a further factor, TFIIG, that is also an essential 
Table 9.1 Transcription initiation factors for RNA polymerase II

\begin{tabular}{|c|c|c|c|}
\hline $\begin{array}{l}\text { Most } \\
\text { common } \\
\text { name }\end{array}$ & $\begin{array}{l}\text { Other names or probable functional } \\
\text { equivalents in various eukaryotic } \\
\text { systems }\end{array}$ & Function & Refs \\
\hline $\begin{array}{l}\text { TFIID } \\
\text { TFIIA }\end{array}$ & $\left.\begin{array}{l}\text { TATA factor, BTF1, DB } \\
\text { STF, AB }\end{array}\right\} \begin{array}{l}\text { B and D } \\
\text { FD and FF } \\
\tau \text { and } \varepsilon\end{array}$ & $\begin{array}{l}\text { Formation of basal } \\
\text { transcription complex } \\
\text { Stimulates TFIID binding but } \\
\text { not always required }\end{array}$ & {$[71,105,107]$} \\
\hline $\begin{array}{l}\text { TFIIB } \\
\text { TFIIE }\end{array}$ & 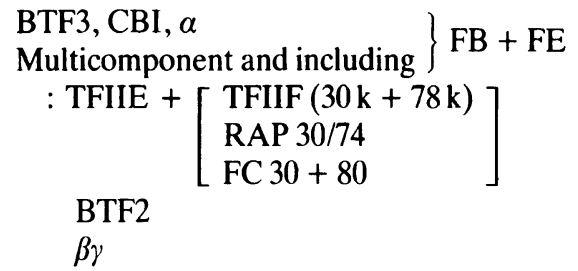 & $\begin{array}{l}\text { Stabilization of } \\
\text { initiation complex. } \\
\text { May include DNA } \\
\text { helicase activity [109]. } \\
\text { The boxed components } \\
\text { are probably the same } \\
\text { two polypeptides. }\end{array}$ & $\begin{array}{l}{[71,106} \\
107108 \\
110]\end{array}$ \\
\hline
\end{tabular}

component of the transcription complex, has been identified [262].

TFIID is absolutely required for transcriptional initiation and its binding is stable through several rounds of transcription [114]. Both binding [111] and the activation of transcription [115] are dependent on a large $C$-terminal region of the protein that stretches from residue 63 to 240 . Within this is a highly basic domain (residues 120-156) and a region (residues 197-240) that has sequence similarity with the -10 -binding region of prokaryotic sigma factor [111, 116].

As well as being pivotal in the formation of the basal transcription factor, TFIID also plays a role in the modulation of transcription. A transcription factor SP1 interacts with the GC box of the UPE and in so doing causes a fivefold increase in transcription. Evidence collected by Pugh and Tjian [117] suggests that the complex of the GC box and SP1 causes stimulated transcription by interacting with TFIID promoter complex via a co-activator (Fig. 9.7). Similarly, the factor CTF activates transcription when it binds to the CAAT box and is again believed to do so by interaction of the complex with TFIID [117]. There are multiple CAATbinding proteins each of which binds to partially overlapping sets of genes [263] but whether they all interact with TFIID is unknown. Other, more specific transcription factors, are, however, thought to act through TFIID. These include the herpes virus activator protein VP16 [118], GAL 4 that regulates the genes encoding the galactose-metabolizing enzymes of yeast [119] and the mammalian activator protein ATF [264].

\subsubsection{Initiation by RNA polymerase III}

\section{(a) Internal promoters for RNA polymerase III}

The promoters for the tRNA and 5S rRNA genes do not lie in their 5'-flanking sequences but within the coding region of the genes themselves (reviewed in [73, 120, 121]). This unexpected finding resulted from the work of Brown and colleagues on the expression of Xenopus 5S RNA genes in 

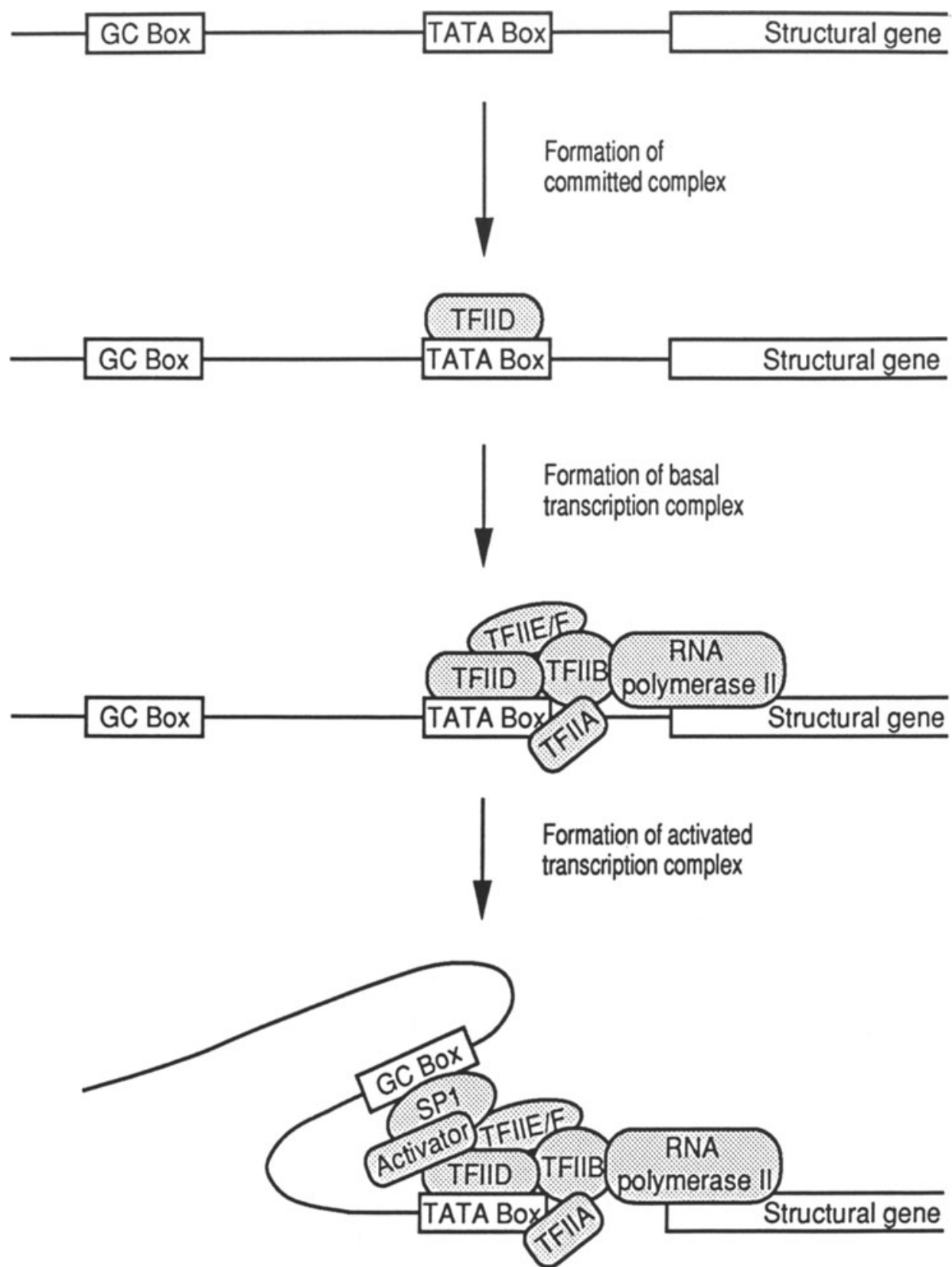

Fig. 9.7 Diagrammatic representation of initiation by RNA polymerase II.

oocytes and in systems for transcription in vitro. They found that the entire $5^{\prime}$ flanking sequence of the gene could be removed without the loss of 5S RNA tran- scription. Furthermore, when they deleted the $5^{\prime}$-end of the coding sequence, they found that 5S-sized RNA was still made from a new start site that corresponded to 

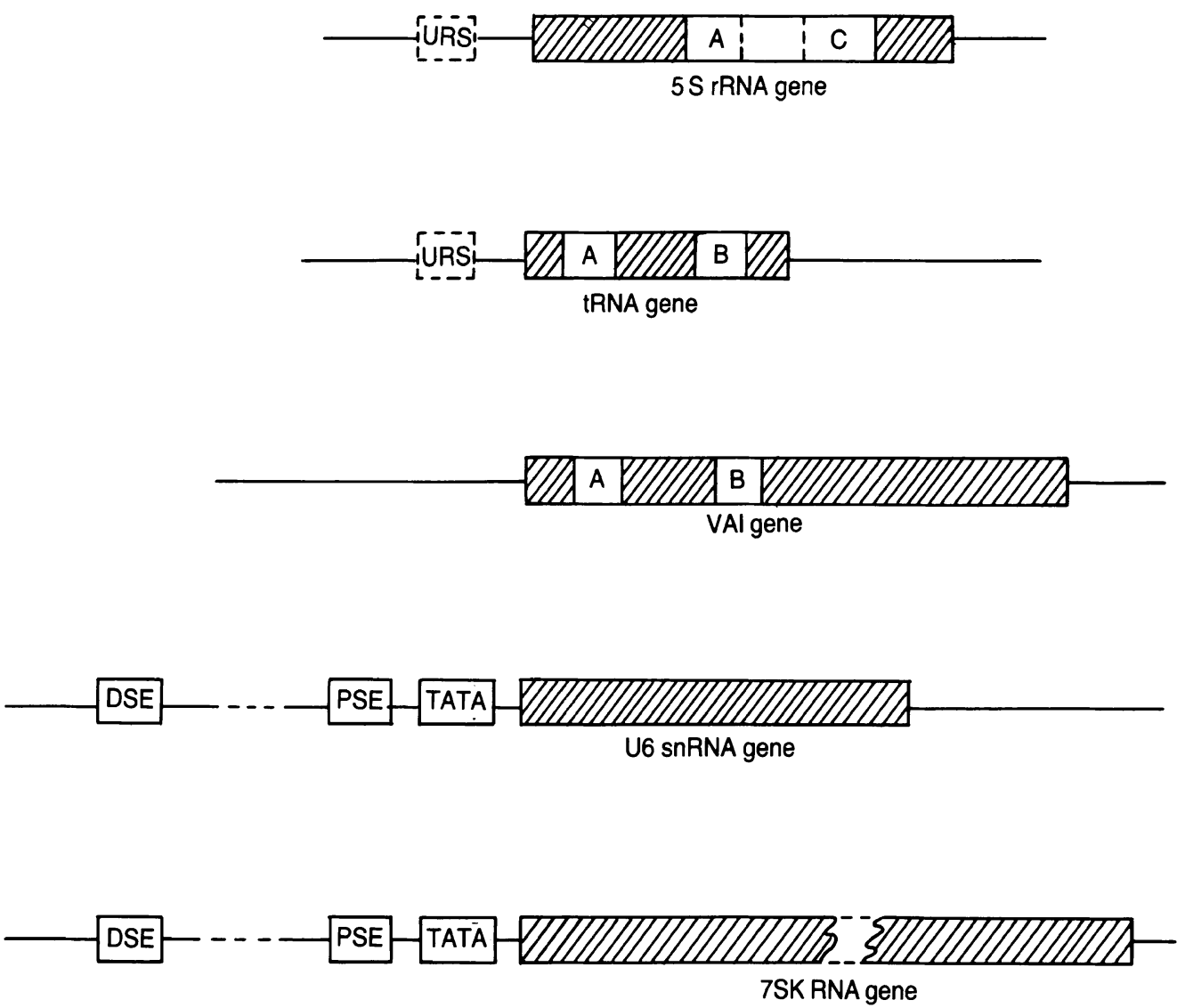

Fig. 9.8 The promoter structure for genes transcribed by RNA polymerase III. The boxes $\mathrm{A}, \mathrm{B}$, and $\mathrm{C}$ are the internal promoter elements of 5S RNA, tRNA and VAI genes. The dotted outline boxes, URS represent upstream regulatory elements that are present in the flanking sequences of some $5 \mathrm{~S}$ and tRNA genes. TATA indicates the presence of RNA polymerase II-like TATA boxes. PSE and DSE are proximal and distal sequence elements of the U6 and 7SK genes.

where the $5^{\prime}$-end of the gene had been. Not until 50 coding nucleotides had been deleted was there a drop in the efficiency of transcription [122]. Subsequent experiments, in which the 3 '-end of the gene was deleted [123], or in which extra nucleotide sequences were inserted into the gene [122], showed that the synthesis of 5S RNA was controlled by a promoter located between residues 50 and 83 of the Xenopus gene. The promoter is known as the internal control region or ICR (Fig. 9.8) and is required and sufficient for transcription. It is not, however, re- cognized by RNA polymerase III [124] but by a transcription factor, known as TFIIIA [125], which specifically interacts with two factor-binding domains at the boundaries of the promoter region [126]. These domains have become known as Block A and Block $\mathrm{C}$ in reference to the two-block promoter of tRNA genes (see below).

TFIIIA was the first eukaryotic transcription factor to be discovered and is the archetype of a group of proteins that interact with DNA through so-called zinc fingers (section 10.5.2). The protein has nine of 


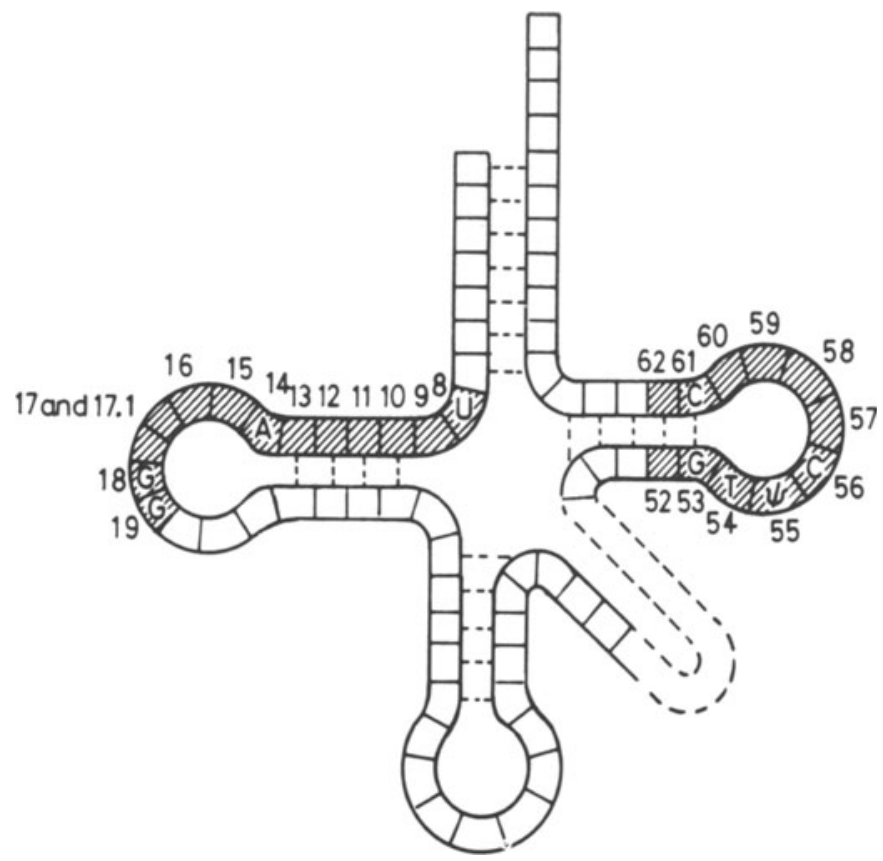

Fig. 9.9 The relationship of the split promoter of tRNA genes to the clover-leaf tRNA secondary structure. The shaded portions of the tRNA molecule and the labelled invariant nucleotides are transcribed from the internal promoter.

these $\mathrm{Zn}^{2+}$-binding domains that jointly interact with approximately five helical turns of the ICR. The interaction is strongest with box C (base pairs $80-97$ ) but also occurs with box A (bp 49-60) and weakly with some intervening regions. Most of the zinc fingers and the DNA binding activity are in the $N$-terminal portion of the polypeptide but this portion of the protein cannot by itself bring about formation of a stable transcription complex. Neither will it permit the cooperative binding that appears to occur between the tandemly arranged $5 \mathrm{~S}$ RNA genes [127]. The binding of TFIIIA is the first stage in the formation of a $5 \mathrm{~S}$ transcription complex and is followed by the sequential binding of TFIIIC and TFIIIB [128]. It is the complete complex that is recognized by RNA polymerase III [128].

Similar studies with tRNA genes have shown that they too have an internal promoter (Fig. 9.8) but in this case it is clearly split into two blocks termed A and B [129]. Block $\mathrm{A}$ extends from nucleotides 8 to 19 and includes the portion of the gene that encodes the tRNA D loop and four invariant nucleotides. The $\mathrm{B}$ block runs from nucleotides 52 to 62 including those encoding the T-loop and five invariant nucleotides (Fig. 9.9). Thus, the invariant nature of some tRNA nucleotides appears to be important both in tRNA tertiary structure (section 12.3.1) and in the initiation of tRNA synthesis. Because of the length heterogeneity of the tRNA variable loop and the presence in some tRNA genes of inserts, the distance between the $\mathrm{A}$ and $\mathrm{B}$ blocks in the gene can vary between 25 and $95 \mathrm{bp}$.

Block $\mathrm{B}$ has no equivalent in the $5 \mathrm{~S}$ gene intergenic promoter but block $\mathrm{A}$ is func- 
tionally equivalent to the $5 \mathrm{~S}$ block $\mathrm{A}$. Conversely, there is no equivalent to the $\mathrm{C}$ block in the promoter of tRNA genes which are not therefore targets for TFIIIA. Instead, the first step in the assembly of a transcription complex on tRNA genes occurs with the binding of TFIIIC to the B block of the promoter. The factor also interacts with the A block. Proteolysis of the yeast TFIIIC (also called Tau) shows that the $300 \mathrm{kDa}$ protein has two functional domains one of which binds to $B$ block and the other to A block [130]. Electron microscopy indicates that between the two domains the protein is very flexible allowing it to adopt a globular or dumbbell shape depending on the separation of the A and B blocks between the 25 and 95 bp minimum and maximum spacing[131]. There is evidence, in at least some systems, that TFIIIC is multicomponent and may include a polypeptide that specifically recognizes tRNA promoters [132]. However, the data are contradictory and await clarification (reviewed in [121]). As with the $5 \mathrm{~S}$ promoter, the binding of TFIIIC is stabilized by TFIIIB so forming a pre-initiation complex that is recognized by RNA polymerase III.

TFIIIB is the protein that correctly positions RNA polymerase III at the start site for the initiation of transcription of both 5S and tRNA genes [133]. Kassavetis et al. demonstrated that, once TFIIIB is associated with the complexes, the factors TFIIIA and TFIIIC can be removed with heparin or high salt, leaving TFIIIB still attached. The partially stripped promoters still permit the accurate initiation of transcription by RNA polymerase III [133]. Thus, TFIIIA and TFIIIC function only as promoter recognition factors that sequester TFIIIB. Footprinting analyses, that show that TFIIIB protects $5^{\prime}$-flanking sequences of genes rather than the internal promoters, support these concepts [134]. (b) Upstream promoters for $R N A$ polymerase III

Although the internal promoters of $5 \mathrm{~S}$ and tRNA genes were unexpected, they nevertheless form a consistent picture whereby the sequential recognition of the promoter by transcription factors leads to the accurate positioning of RNA polymerase III. The adenovirus VA RNA gene, which is transcribed by RNA polymerase III into a RNA that regulates viral gene expression, supports the concept. Like tRNA genes, it has $\mathrm{A}$ and $\mathrm{B}$ block internal promoters (Fig. 9.8). However, it has recently become clear that this picture of RNA polymerase III transcription is too simplistic. Many 5S genes have been found to have $5^{\prime}$-sequences that dramatically influence the rate of their transcription. Furthermore, the elements involved are homologous in sequence and location with the TATA box of the RNA polymerase II promoter [135]. Other genes that are transcribed by RNA polymerase III blur the picture even more dramatically in that they have no internal promoters (reviewed in [136]). Thus, U6 snRNA and 7SK RNA genes have TATA boxes together with other upstream elements that are more usually associated with the enhancement of RNA polymerase II transcription (Fig. 9.8). These include proximal elements, that may function to position TFIIIB and thus RNA polymerase III [137], but are nevertheless homologous to the proximal elements of the snRNA genes transcribed by RNA polymerase II. In both Xenopus and plants it appears that the distance between the TATA box and the upstream element in snRNA genes is critical in determining whether they are recognized by RNA polymerase II or III $[138,270]$. The promoters of U6 and 7SK genes also include distal elements that may be equivalent to enhancers (Fig. 9.8). In 7SK genes these 
include an essential CACCC motif that is similar to several eukaryotic regulatory elements [139]. Similarly, the distal element of U6 snRNA genes includes an octamer motif like that controlling the transcription of immunoglobulin and histone genes by RNA polymerase II [140]. Clearly these findings cloud the differences between the two polymerases and suggest that they evolved from a common ancestor.

(c) TFIIIA may regulate the expression of $5 \mathrm{~S}$ rRNA genes

There is evidence that the developmental regulation of oocyte and somatic 5S RNA gene expression in Xenopus may be mediated through transcription factor TFIIIA. Oocytes express 5S RNA from the abundant oocyte $5 \mathrm{~S}$ genes in the presence of high concentrations of TFIIIA whereas somatic cells have low concentrations of TFIIIA and transcribe 5S RNA from the low abundance family of somatic 5S RNA genes. Wolffe and Brown [141] have explained the differential regulation by differences in the stability of the TFIIIA-DNA complexes. They suggest that, because the somatic promoter-TFIIIA complexes are more stable, they are able to compete more effectively for the declining quantities of the factor that are present after the fertilization of the oocyte. However, Blanco et al. [142] have reported two different TFIIIA activities in this system. They claim that transcription of oocyte 5S RNA requires a $39 \mathrm{kDa}$ form of the factor whereas a $42 \mathrm{kDa}$ form activates the somatic genes and represses the oocyte genes.

\subsubsection{Initiation by RNA polymerase I}

The transcription of pre-rRNA represents approximately half of all cellular RNA synthesis and is regulated in response to changes in growth and metabolism (reviewed in $[74,265]$ ). The high transcription rate may be presumed to reflect many features of the rDNA genes. There is a high gene dosage and, from yeasts to man, the rDNA is arranged in multiple tandem copies with the coding regions separated by intergenic spacers (section 8.4.3). The genes are concentrated in the nucleolus as is RNA polymerase $\mathrm{I}$, the enzyme that apparently transcribes only pre-rRNA. Transcriptional regulation is focused in the intergenic spacer (formerly, but mistakenly, called the non-transcribed spacer). It contains at least three controlling elements; proximal promoters, upstream promoter elements and terminators. In many cases, upstream sequences also include elements with many of the properties of the enhancers of RNA polymerase II.

RNA polymerase I was the last of the eukaryotic nuclear RNA polymerases for which in vitro and in vivo transcription systems were developed [143], in part because, unlike polymerase II and III, this enzyme is very species-specific. Thus, mouse RNA polymerase recognizes its own promoter complex and that of closely related species like rat but it will not recognize that of human. Similarly, the human enzyme will recognize human and rhesus transcription systems but not that of mouse $[144,145]$. Presumably, the singular specificity of the enzyme has permitted this evolutionary drift.

Notwithstanding species specificity, rDNA promoters of vertebrates share many common features (Fig. 9.10). In mammals, the core promoter element (CPE, also called the proximal promoter) overlaps the transcribed gene and spans from -31 to +6 with respect to the transcription start site. A second distinct but interacting domain, called the upstream control element (UCE) 
(a) The Intergenic Spacer of Xenopus laevis rDNA

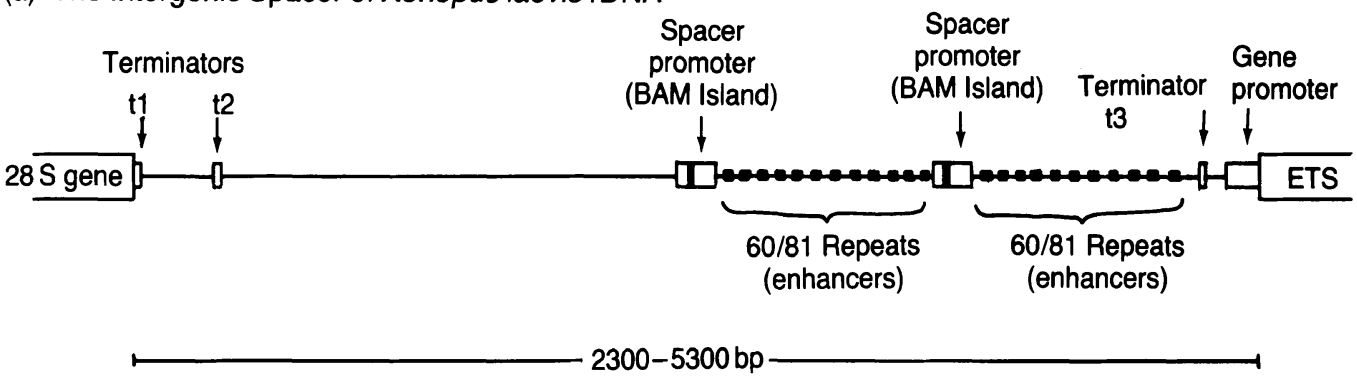

(b) The Intergenic Spacer of mouse rDNA

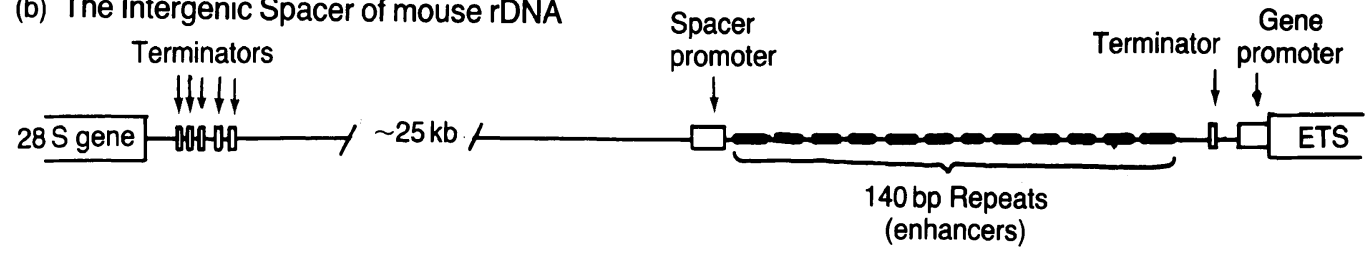

$\longmapsto \sim 30000 \mathrm{bp}$

Fig. 9.10 The intergenic spacers of rDNA from (a) Xenopus laevis and (b) mouse. The black bar in the Xenopus spacer promoters indicates that enhancer elements occur within them. ETS is the external transcribed spacer (section 8.4.3).

or upstream promoter element (UPE) is located between -107 and $-187[146,147]$. The CPE is necessary for transcription and in vitro is sufficient for basal rates of rRNA synthesis. The UPE is required, however, for efficient transcription both in vitro and in vivo [148-150]. The intergenic spacers of some species contain a series of repetitive sequences upstream of the promoter that are, in effect, multiple duplications of promoter elements. Thus, in Xenopus, the core promoter again spans the transcription start site $(-14$ to +4$)$ but in addition there are multiple promoter-like elements that are approximately $90 \%$ homologous to the promoter and are located in the so-called Bam islands (Fig. 9.10). Drosophila likewise has multiple internally repetitious promoters in its intergenic spacer [151, 152]. Transcription can initiate from within these intergenic promoters and the resultant transcripts terminate upstream of the true gene promoters (reviewed in [265]); however the function of the transcripts, if any, is a matter of speculation.

In addition to the promoter-like elements, the Xenopus intergenic spacer contains repetitive short sequences, the $60 / 81 \mathrm{bp}$ elements, that are clustered in tandem (Fig. 9.10) and which stimulate transcription when placed at a variable distance from the promoter and when placed in either orientation [153, 154]. They are thus analogous in their activity, but perhaps not in their mechanism, to the enhancers of RNA polymerase II (section 10.4). A $140 \mathrm{bp}$ repeated element between the core and upstream promoters of mouse rDNA (Fig. 9.10) has also recently been shown to have an enhancer-like function [155] and enhancing elements have also been detected in rat and Drosophila [265]. 
At least two protein transcription factors are required for pre-rRNA synthesis. In rat, footprinting experiments have shown that the factors SL1 and SF1 interact with both the core and upstream promoters. Binding to and transcription from the proximal promoter is much more efficient than that from the upstream elements [156] so it is uncertain what the function of the upstream promoters may be. Moss [157] has suggested that they function as sinks for RNA polymerase but it is also possible that they are alternative promoters the use of which is associated with differential control of rDNA gene expression.

Rat SF1 is apparently homologous with the factor called UBF in human cells and with $x U B F$ of Xenopus [158, 159]. The proteins recognize the same DNA sequence elements [160] and cannot therefore be responsible for species specificity of promoter recognition. Factor SL1, on the other hand, is a good candidate for the source of species specificity. Human SL1 (hSL1) will cause a mouse in vitro transcription system to recognize a human promoter [161]. Similarly, rat SL1 (rSL1) will reprogramme a human transcription system to recognize a rat promoter [156]. Bell et al. [162] have shown that mouse and human RNA polymerase I and UBF are functionally interchangeable but SL1 are distinct in both their binding and transcriptional activities. Thus, although mouse SL1 will selectively interact with DNA in the absence of UBF [162], human SL1 does not recognize DNA and associates with the promoter only by interaction with UBF [163]. A strong cooperative complex between the two proteins is critical to transcriptional activation $[162,164]$. UBF has been purified from both human and Xenopus cells and shown to have multiple domains. The DNA binding domains exhibit the same specificity but the domains that interact with SL1 differ [165]. Thus, it appears that species specificity resides in SL1 and its interaction with both UBF and DNA. The Xenopus $60 / 81$ enhancer repeats (Fig. 9.10) exhibit considerable sequence homology with the UBF-binding region [266] and apparently act by enhancing the formation of UBF-SL1 transcription complexes [267].

In addition to detecting factors that may be homologous to those described above, three groups have detected factors that interact with RNA polymerase I [166-168]. That called TIF-1A by Grummt and colleagues, interacts with the enzyme and converts it into an active holoenzyme that has rDNA promoter specificity [167]. It thus behaves like bacterial sigma factor. These workers have also shown that dephosphorylation of RNA polymerase I abolishes its specificity for rDNA promoters. Another factor, designated TFIC by Thompson and coworkers [168, 169] is also tightly associated with RNA polymerase I and reduced levels of it have been implicated in the reduced transcription of rRNA in glucocorticoid-treated lymphosarcoma cells.

A further controlling influence on the initiation of transcription from tandemly arranged rRNA genes are the terminator sites of the previous gene which, in addition to their termination activity, are in some cases able to stimulate the adjacent gene promoter (reviewed in [170]). Thus, it is now known that, in Xenopus, RNA polymerase I transcribes right across the intergenic spacer to a terminator called $t_{3}$ that is approximately $60 \mathrm{bp}$ upstream of the promoter for the next transcription unit (section 9.5.3). It has been suggested that it may act with the promoter in an interdependent complex bringing about the termination of one transcription unit and the initiation of the next. Mammalian RNA polymerase terminates after transcribing a much shorter distance into the intergenic 
spacer (section 9.5.3) but there are again extra terminator sequences close to the next promoter. They may well have two functions; the termination of transcripts that have initiated within the intergenic spacer and exerting a positive influence on the initiation of the next transcription unit. It is suggested that RNA polymerase is 'handed over' from the terminator to the promoter. However, recent experiments by Labhart and Reeder [171] have demonstrated that preventing the enzyme from reaching the Xenopus $t_{3}$ terminator had no effect on the density of polymerase molecules that collected at the $5^{\prime}$-ends of genes.

\subsection{TERMINATION OF TRANSCRIPTION IN EUKARYOTES}

Termination of transcription in eukaryotes is not well understood. Often it is difficult to even be sure of the relationship between observed 3'-termini of newly made RNA molecules and the real point at which transcription terminates. This is especially so with the transcripts of RNA polymerase II, the majority of which are post-transcriptionally modified by $3^{\prime}$-polyadenylation. The only method currently available to identify termination sites is run-on or run-off transcription (both names are confusingly used for the same process). By using purified nuclei for transcription in vitro, the synthesis of partially transcribed and still nascent RNA molecules is continued with the incorporation of radioactive nucleotides. After purification, the radioactive RNA is hybridized to fragments of DNA that correspond to the $3^{\prime}$-end and the $3^{\prime}$-flanking sequences of the mRNA encoding sequence. In this way, it has been demonstrated that many genes are transcribed well past their apparent $3^{\prime}$-termini and are then subject to processing to generate their $3^{\prime}$-termini (processing is considered in sections 11.5, 11.6 and 11.7).

\subsubsection{Termination by RNA polymerase II}

\section{(a) Polyadenylated $m R N A$}

Use of the run-off transcription assay (section A.11) has demonstrated that RNA polymerase II characteristically terminates at heterogeneous sites up to several thousand base pairs beyond the polyadenylation site [172]. Thus, the termination of mouse $\beta$-globin occurs about $1 \mathrm{~kb}$ past the end of the gene [173] whereas mouse $\alpha$-amylase transcripts terminate at multiple sites $2-4 \mathrm{~kb}$ past the 3 '-terminus [174]. Proudfoot [175] has tabulated the run-off characterized termination of other genes and has reviewed termination by RNA polymerase II.

Section 11.5.1 describes how two sequence elements of polymerase II transcripts, the AAUAAA and a GC-rich sequence motifs, are specific recognition signals for the $3^{\prime}$-processing of pre-mRNA. It has become clear that these same elements are also involved in transcriptional termination. This was first indicated in a patient with $\alpha$-thalassaemia in whom a base change in the $\alpha 2$-globin gene converted the AATAAA motif into AATAAG. This not only inactivated the processing of $\alpha 2$-globin pre-mRNA but also caused transcription to continue well past the normal termination sites [176]. Similarly, the AATAAA element of a mouse globin gene could be used in a gene construct to promote the termination of the adenovirus E1A gene but failed to do so if changed by point mutation [177]. Hybrid gene constructs in SV40 and polyoma have also been used to demonstrate that termination requires a functional $3^{\prime}$-processing site and that both 
the AATAAA and the GC-rich elements were required [178, 179]. Furthermore, the stronger the processing site the more efficient was the termination.

Two models have been put forward to account for the coupling between $3^{\prime}$ processing and termination. Darnell and coworkers suggest that a specific elongation factor could be released from RNA polymerase II during its passage over the processing signal sequences. This, they suggest would destabilize elongation and cause random termination [177]. The model most supported by the available evidence, however, is that the $3^{\prime}$-terminus is formed by the endonucleolytic cleavage of a transcript while it is still being synthesized. Cleavage is anticipated to occur at the processing site while RNA polymerase is still advancing a considerable distance downstream [172, 178]. After cleavage, the newly formed 3 '-terminus becomes the site for polyadenylation (section 11.5.1) while the new 5 -terminus is not capped and is vulnerable to degradation by exonuclease. Proudfoot [175] has suggested that three factors may contribute to the eventual termination of transcription and release of the polymerase. These are the exonuclease activity, a RNA: DNA helicase that might be required to unwind the nascent RNA:DNA hybrids and pausing sites on the DNA required to slow the progress of RNA polymerase.

\section{(b) snRNA genes}

Termination of the transcription of the genes for snRNAs (snRNAs themselves are described in section 11.2) appears to occur at or close to the $3^{\prime}$-terminus of the mature snRNA [180, 181]. Three sequence elements are apparently required for this precise recognition event. The first of these is a preserved motif GTTTN $_{0-3} \mathrm{AAA}$ $\mathrm{G} / \mathrm{A} N \mathrm{NAGA}$ in the immediate $3^{\prime}$-flanking region of snRNA genes. The second is an internal sequence close to the $3^{\prime}$-end of all snRNA genes that is potentially able to form a stem-loop structure and the third element is the promoter of snRNA genes. The role of the promoter elements is not understood but snRNA termination signals do not work if combined in gene constructs with nonsnRNA promoters. For example, RNA polymerase II initiating at an adenovirus late promoter, will transcribe through an snRNA termination sequence to terminate at a downstream polyadenylation site [182]. It thus seems likely that initiation at a snRNA promoter is accompanied by the incorporation into the initiation complex of a specific factor that then promotes disengagement of polymerase at the snRNA termination site.

\section{(c) Histone genes}

Histone genes illustrate a third type of termination by RNA polymerase II. As described in section 11.5.2, the 3 '-processing of histone transcripts involves the recognition of a series of conserved elements by a number of factors that include snRNA U7. Termination of transcription occurs well downstream of these processing sites and, in contrast to polyadenylated pre-mRNA, the two processes can be independent of each other. Thus, the conserved processing signals of some histone genes can be removed without affecting termination and it has recently been shown that termination occurs in an A-rich region [183]. The motifs are close to but separate from the processing signals and, when placed in a globin gene intron, they cause premature termination of transcription. In contrast to these data however, recent studies with the mouse 
H2A gene have shown that a processing site is required for termination [268].

\subsubsection{Termination by RNA polymerase III}

Termination of 5S RNA transcripts by RNA polymerase III occurs in a single consensus sequence that consists of a run of four or more $\mathrm{T}$ residues in the non-coding strand and is surrounded by GC-rich sequences [184]. Similar terminator sequences occur immediately or soon after the coding regions of almost all known tRNA genes, and mutations that create strings of four or more $\mathrm{T}$ residues within a gene cause premature termination [185, 186]. Deletion of the $T$ clusters from the 3 '-flanking regions causes readthrough beyond the normal 3 '-terminus. Similar sequence motifs occur at the $3^{\prime}$-ends of other class III genes, however yeast RNA polymerase may require longer runs of Ts because the recognition sequence of most of its 5S RNA genes consist of $29 \mathrm{~T}$ residues.

Termination in vitro is stimulated by a highly conserved, $50 \mathrm{kDa}$ nuclear phosphoprotein called La. Sera from patients with autoimmune disease often carry antibodies to $\mathrm{La}$ and cell extracts depleted of the protein by the antisera lose the ability to transcribe class III genes [187, 188]. Purified La protein restores transcriptional activity to these extracts and the protein binds to the nascent polymerase III transcripts. Specifically, it binds to the U-rich 3 '-ends of the RNAs that are created by transcription of the oligo(T) termination signal [189]. Gottleib and Steitz [190] have shown that La not only binds to the nascent RNA but facilitates termination. Furthermore, Bachmann et al. [191] have demonstrated that it is a nucleic acid-dependent ATPase that is capable of using phosphodiester bond energy to melt RNA:DNA hybrids. It thus resembles the prokaryotic termination factor, rho (section 9.2.1).

\subsubsection{Termination by RNA polymerase I}

The ribosomal genes of Xenopus have three major sites that have been associated with RNA 3'-end formation and are designated $t_{1}, t_{2}$ and $t_{3}$ (Fig. 9.10). Their relationship with termination was first demonstrated by Labhart and Reeder [192] who showed that $t_{1}$ was at the $3^{\prime}$-end of 28S RNA but was not a terminus for transcription. Instead, transcription continued into the intergenic spacer, initially a further 235 bp to $t_{2}$. However, $t_{2}$ did not cause polymerase release either; rather it formed a boundary between relatively stable and very unstable transcript. Transcription continued from $t_{2}$ across the intergenic spacer to $t_{3}$ just $215 \mathrm{bp}$ upstream of the initiation site for the next tandemly arranged rRNA gene and about $60 \mathrm{bp}$ from its promoter. The transcript between $t_{2}$ and $t_{3}$ was rapidly degraded and was only detected by run-off transcription or electron microscopy. Thus, $\mathrm{t}_{2}$ is a processing site and it defines the 3 '-end of the largest relatively stable precursor, 40S pre-RNA. The true terminator, $t_{3}$, is a $12 \mathrm{bp}$ element that is conserved between different amphibia [193]. Within the $12 \mathrm{bp}$ is a $7 \mathrm{bp}$ sequence, GACTTGC, that is also present in $t_{2}$. In fact, $t_{2}$ can be converted into a $\mathrm{t}_{3}$-like terminator by a single base change downstream of the GACTTGC box [194]. McStay and Reeder [195] have concluded that $t_{3}$ and the adjacent promoter of the next transcription unit act as one interdependent complex bringing about the termination of one transcription unit and the initiation of the next. They have also detected a DNA-binding protein that 
interacts with the $t_{3}$ sequence and is required for termination [196].

Termination elements have also been identified in mammalian rDNA, particularly that of the mouse where a repetitive $18 \mathrm{bp}$ motif, known as the Sal box (AGGTCGACCAG $1 / \mathrm{T} /{ }_{\mathrm{A}}^{\mathrm{T} T C C G}$ ) constitutes the termination signal (Fig. 9.10). RNA polymerase I specifically terminates 565 nucleotides downstream of the 3 '-end of 28S RNA and $11 \mathrm{bp}$ upstream of the first termination signal $[197,198]$. The $3^{\prime}$-end of the transcript is then trimmed by 10 nucleotides to produce the 3 -terminus of the first relatively stable precursor, $45 \mathrm{~S}$ RNA [199]. Termination again requires the binding of a specific factor (TTF-1) to the Sal box sequence [200]. The protein is obviously strongly conserved as it will function in species as divergent as yeast and mouse but it has no effect on termination by RNA polymerases II and III. However, it should be emphasized that, in contrast to the prokaryotic rho factor and to La protein in termination by RNA polymerase III, the factors so far identified for termination by RNA polymerase I interact with the DNA not the nascent RNA. Parallel studies of the termination of human rDNA transcription have identified a shorter, $11 \mathrm{bp}$, recognition motif (GGGTCGACCAG) that corresponds to the proximal part of the mouse terminator [201]. The protein that binds to this element exhibits different electrophoretic mobility but is otherwise very similar to the mouse protein [201].

As in Xenopus, mammalian rDNA intergenic spacers contain multiple terminator sequences including copies close to the initiation site for the next tandemly arranged transcription unit. These appear to have two functions. They terminate transcripts that have initiated in the intergenic spacer and they exert a positive effect on the initiation of the next rRNA gene. The possible importance of this in initiation is discussed in section 9.4.3.

\subsection{DOES THE NUCLEOSKELETON PLAY A ROLE IN TRANSCRIPTION?}

Studies with in vitro transcription systems and solubilized RNA polymerase argue that transcription is initiated, as described in the preceding sections of this chapter, by a diffusible enzyme binding to a promoter and then moving along the DNA. Cook [202] and others have pointed out that the evidence for this concept of transcription comes from extracts and nuclear fractions the preparation of which required the use of hypotonic salt concentrations. The aggregation of chromatin components precludes the use of isotonic or hypertonic solutions under most circumstances but preparations that do employ them suggest that active RNA polymerase is associated with the nucleoskeleton and is not freely diffusible (reviewed in [202]).

The structure and function of the nucleoskeleton is controversial and various structures that can be isolated (nuclear matrix, nuclear scaffold, nucleoid cages) may be derived from it to a greater or lesser extent. Thus, the nuclear matrix is the remnant that remains when nuclei are sequentially extracted with high salt concentrations $(2 \mathrm{M}$ $\mathrm{NaCl}$ ) and non-ionic detergent (1\% Triton) and are then treated with DNase and sometimes with RNase. When viewed by electron microscopy, such samples retain the overall outline of nuclei but are composed entirely of a network of thin proteinaceous fibres together with residual nucleolar structures, nuclear pores and connecting lamina.

Accumulating but conflicting data suggest that the nucleoskeleton may be intimately associated with both transcriptional and 
post-transcriptional processes [203]. DNA appears to be organized into a series of supercoiled loops anchored to the matrix and, when the loops are cleaved with endonucleases, the DNA sequences that remain attached to the matrix can be analysed. In this way the active ovalbumin [204, 205], conalbumin [204], globin [206, 207] and vitellogenin genes [208] have all been shown to be preferentially associated with the matrix. The data are not, however, universally accepted. Kirov et al. [207] have suggested that the apparent association of active genes with the matrix may be an artifact created by the association of active genes with proteins that are resistant to the high-salt methods of preparing the matrix. When DNase I is used in the absence of high salt no such association is observed. Mirkovitch et al. [209], also using a low-salt extraction method, have shown that histone gene clusters are attached to the matrix by an AT-rich region in the spacer between the clusters. They report, however, that the attachment is independent of transcription. Conversely, Cook and colleagues [210, 211] use gentle isotonic methods to make preparations of nucleoskeletons and find that RNA polymerase, nascent transcripts and the genes being transcribed are closely associated with it. Their method avoids the problems of aggregation by encapsulating cells in agarose microbeads. The beads can then be extracted with physiological buffers containing non-ionic detergent so that the cytoplasmic proteins and most RNA diffuses out to leave encapsulated chromatin surrounded by the nucleoskeleton. Transcriptional rates assayed in these preparations are twice those of conventional nuclei. Several groups have more precisely located matrix-associated regions (MARs) or scaffold-associated regions (SARs) and have shown that they coincide with the boundaries of DNase sensitive gene domains
[212-214] or that they flank specific regulatory elements $[215,216]$. Sippel and coworkers [217] have shown that when a reporter gene is flanked by a scaffold attachment site of the lysozyme gene, its expression in stably transfected cells is significantly elevated and is independent of chromosomal position.

Perhaps the most radical suggestion arising from these studies is a model of transcription in which it is suggested that the template moves past a polymerase molecule anchored to the nucleoskeleton. The skeleton is thus seen as the active site of transcription [202]. At best, the evidence to support the model is circumstantial but it does draw attention to uncertainties in the accepted concepts. The nuclear matrix has also been implicated as the site for the splicing of pre-mRNA and for the transport of mRNA to the cytoplasm (section 11.3.1).

Similar arguments to those discussed above centre on whether, in the mitotic chromosome, potentially active genes are associated with the so-called chromosomal scaffold (e.g. [218]).

\subsection{THE TRANSCRIPTION OF MITOCHONDRIAL AND CHLOROPLAST GENES}

The genomes of subcellular organelles are expressed by their own transcriptional machinery that includes specific RNA polymerases. Initially, the characterization of these systems lagged well behind those of nuclear transcription because of the low amounts of the enzymes and the lack of specific assays for initiation. However, the enzymes have now been purified from several sources and the triphosphates at the $5^{\prime}$-termini of their transcripts can be specifically labelled by the nuclear mRNAcapping enzyme, guanyltransferase. 


\subsubsection{Mitochondrial transcription}

RNA polymerases have been purified and characterized from the mitochondria of man, Xenopus and yeast (reviewed in [219]). The amphibian and yeast enzymes consist of a core enzyme and a specificity factor that confers promoter specificity. The human enzyme is similar except that the core enzyme alone exhibits some promoter specificity but requires a factor called mitTF for efficient transcription. The human promoters consist of two components; a core promoter and an upstream region. The factor mitTF binds to the upstream region and in so doing is presumed to increase the efficiency with which the core enzyme interacts with the promoter $[220,221]$.

As described in section 8.5.1, vertebrate mitochondrial genomes are very compact and almost lack the intergenic spacers that would normally contain promoters. In fact, the whole genome is divergently transcribed from a single region that includes two independent promoters for leftward and rightward transcription (most genes are encoded on the so-called heavy DNA strand with just a few tRNA genes on the light strand). Furthermore, the promoters are closely associated with the primary origin of DNA replication and are within the D loop in which a short nascent DNA strand represents the resting stage of DNA replication (section 6.11.4). It has been suggested that vertebrate mitochondrial RNA polymerases serve a dual function in transcription and replication. Thus, DNA synthesis is seen as initiating with the synthesis of a primer RNA at one of the transcriptional promoters. The switch from RNA to DNA synthesis is then believed to occur within a 90 nucleotide region that encompasses three previously identified sequence blocks; CSB-I, CSB-II and CSB-III that are conserved in vertebrate mitochondrial DNAs [221].

Other vertebrate species (mouse and Xenopus) appear to have mitochondrial promoters of similar organization to that of man. In yeast, however, there are differences that reflect the less compact genome. All but one of the tRNA genes are on the same strand in the mitochondrial DNA of the yeast, $S$. cerevisiae, and some of the genes possess their own promoter whereas others are expressed from shared promoters. Each promoter consists of a block of 11 nucleotides with the sequence A $/ \mathrm{T}$ TATATAAGTA. Transcription begins at the last $\mathrm{A}$ (position +1 ) of the sequence. The core enzyme reacts weakly with the core element or any other DNA and the $43 \mathrm{kDa}$ specificity factor does not interact with DNA [222]. However, the two components co-operate together to form an initiation complex [223]. The 11 nucleotide promoter sequence also occurs in the DNA replication origin so it seems likely that in yeast, as in vertebrates, mitochondrial RNA polymerase may play a role in DNA synthesis $[219,221]$. The yeast promoter does not appear to be strongly conserved in other fungi [224], and neither the nature nor the number of mitochondrial promoters is well characterized in higher plants [225].

\subsubsection{Chloroplast transcription}

Chloroplast gene arrangement and expression has much in common with that of prokaryotes (reviewed in [226-228]). Clusters of genes in some cases exhibit homology with gene sets in the cyanobacterial genome from which they are believed to have evolved. Most of the genes in these clusters are co-transcribed into polycistronic mRNAs from promoters 
that appear to be homologous with the prokaryotic -10 and -35 motifs. Many of the promoters can in fact be recognized by E. coli RNA polymerase. However, some chloroplast genes do not have typical prokaryotic promoters and there is evidence that chloroplasts may have more than one RNA polymerase. A polymerase that is isolated as a transcriptionally active DNAprotein complex, preferentially synthesizes chloroplast rRNA and may be a single polypeptide [229, 230]. Other preparations appear to be multi-subunit enzymes and may specifically transcribe the tRNA and mRNA genes of chloroplasts [231]. It is possible, however, that these apparent differences will prove to be artifacts of the procedures used and the impurity of the preparations [228].

\subsection{TRANSCRIPTION OF DNA VIRUSES}

\subsubsection{Prokaryotic DNA viruses}

Some bacteriophage redirect the RNA polymerase of their host to transcribe the phage genome (sections 10.1.6 and 10.3.2). Others, at least in part, employ their own enzymes (for a general review of these viral RNA polymerases, see [232]).

The RNA polymerase of bacteriophage $\mathrm{T} 7$ and its relatives (T3, SP6, gh- 1 ) is encoded by one of the so-called early genes of the virus and is transcribed by host RNA polymerase early in the infective cycle (reviewed in [233]). The transcript is translated by the host's protein-synthesizing system and viral polymerase is then responsible for the transcription of the middle and late viral genes from class II and class III promoters, respectively. These pro- moters share a strongly conserved $23 \mathrm{bp}$ consensus sequence, located at -17 to +6 with respect to the transcription start site and for which $\mathrm{T} 7$ polymerase has a stringent specificity [234]. Class III promoters have a second conserved motif in the region -22 to -18 [235].

The T7 enzyme consists of a single polypeptide of $98000 \mathrm{kDa}$. Transcription is exclusively from promoters on the $r$ stand of the viral DNA and occurs at a very fast rate of 200 nucleotides per second. It selectively transcribes DNA that is linked to the $23 \mathrm{bp}$ promoter, binds to one face of the DNA [269] and all transcripts start with the sequence pppGGG [236]. Bacteriophage T3 RNA polymerase is closely related to that of $\mathrm{T} 7(82 \%$ amino acid identity). It is, however, specific for its own promoter motif which is also a 23 bp sequence but differs from that of $\mathrm{T} 7$ particularly in the region -10 to -12 [237].

Bacteriophage $\mathrm{N} 4$ does not rely on the host enzyme for early gene transcription but carries its own, very large $\left(M_{\mathrm{r}} 350000\right)$ single polypeptide, RNA polymerase within the bacteriophage particle.

\subsubsection{Eukaryotic DNA viruses}

Many of the double-stranded DNA viruses that infect animal cells, including SV40, polyoma, papilloma, adenovirus and Epstein Barr virus (EBV), rely on host RNA polymerases to express their genetic programme. For instance, the genes of EBV virus are expressed from 24 promoters by RNA polymerase II [238] and from two promoters by RNA polymerase III [239]. The genomes of these viruses include enhancer elements and they encode regulatory proteins that allow them to hijack their host's transcriptional machinery; often 
ensuring that their genes are expressed in multi-tiered cascades. The regulatory mechanisms that control these processes in SV40 and adenovirus are discussed in sections 10.4 .4 and 10.4.8, respectively.

Relatively few eukaryotic DNA viruses employ viral proteins for replication and transcription but the poxviruses are exceptions; presumably because they replicate in the cytoplasm of their host cells. They are large viruses. Thus, vaccinia virus (Copenhagen strain) has a genome of $191636 \mathrm{bp}$ that includes 198 open reading frames of at least 60 amino acids (vaccinia virus transcription is reviewed in [240] but many of the most recent findings described below are sited in a review of a symposium that was devoted to poxviruses [241]). The enzymes encoded in the vaccinia genome include those required for transcription (RNA polymerase, poly (A) polymerase and capping enzyme) and those needed for replication (DNA polymerase, DNA ligase, type I topoisomerase, thymidine kinase and thymidylate kinase).

When the virion is assembled, the enzymes required for early gene expression are encapsulated in the core. The uncoating process that follows infection liberates these proteins, transcription commences and results in the production of capped, polyadenylated mRNAs that are translated on host cell ribosomes [240]. Vaccinia RNA polymerase has been purified and characterized. It has a $M_{\mathrm{r}}$ of 425000 , comprises seven subunits, is resistant to $\alpha$-amanitin and, in vitro, is dependent on $\mathrm{Mn}^{2+}$ ions for activity [242]. The two largest subunits show sequence homology with those of eukaryotic RNA polymerases and one small subunit exhibits homology with the elongation factor S-11 [241]. The polymerase does not of itself possess promoter specificity and recognition of the early gene promoters depends on vaccinia early transcription factor ( $\mathrm{vETF}$ )
[243]. The factor consists of two subunits of 73 and $82 \mathrm{kDa}$ of which the smaller has homology to DNA helicase whereas the larger has the leucine zipper and zinc-finger domains that are associated with many transcriptional factors (section 10.5). Footprinting experiments (section A.9.2) show that the factor interacts with the -13 to $-28 \mathrm{~A}$-rich promoter sequence, $\mathrm{A}_{5} \mathrm{TGA}_{8}$, that specifies the initiation of early genes. It also interacts with the region +7 to +10 . When interacting with the factor the promoter assumes the conformation of bent DNA and the major groove widens in the region of the initiation site. ATP destabilizes the initiation-factor-polymerase complex and it has been suggested that the hydrolysis of ATP releases the complex from the promoter and allows the polymerase to initiate elongation (from [241]).

Termination of the early genes occurs at the sequence TTTTTNT. It requires another two-subunit protein which allows the transcriptional complex to recognize the $\mathrm{U}_{5} \mathrm{NU}$ transcript of the termination motif. Termination is induced approximately 50 nucleotides further downstream. The termination factor also functions as a capping enzyme; its large subunit possesses triphosphatase and guanyl transferase activity whereas the small subunit possesses methyl transferase activity [244, 245].

Among the proteins synthesized from the expression of the early genes is an intermediate transcription factor (vITF). It confers specificity on the viral RNA polymerase for the intermediate gene promoters and these are expressed after the early proteins induce further uncoating of the viral DNA. Similarly, the genes transcribed in this intermediate class include those encoding three late gene transcription factors (vLTFs). They cause the polymerase to recognize the promoters of the so-called late genes [240, 241]. 


\subsection{THE REPLICATION OF RNA VIRUSES BY RNA-DEPENDENT RNA POLYMERASE (REPLICASE)}

\subsubsection{RNA bacteriophages}

The RNA bacteriophage R17, Q $\beta$, MS2 and f2 have 3600-4500 nucleotide, singlestranded RNA genomes which function both as a mRNA from which viral proteins are translated, and as a template for a RNAdependent RNA polymerase (replicase). Part of the replicase is translated from the infective $(+)$ strand of the viral RNA which it then copies into $(-)$ strands. These are then also copied to produce more $(+)$ strands for packaging into progeny infective bacteriophage.

Replicase transcribes RNA from its 3 '-end, initiating a new RNA chain with a 5 '-GTP and continuing its synthesis in a $5^{\prime} \rightarrow 3^{\prime}$ direction. It therefore moves along the viral genome in the opposite direction to the ribosomes that are reading it as a mRNA. In vitro, a RNA primer can replace GTP in initiating synthesis. The purification and properties of $\mathrm{Q} \beta$ replicase have been reviewed [246] and the functional domains of the enzyme have been mapped [247]. The enzyme consists of four subunits of which subunit II is encoded by the viral genome whereas the others are normally part of the host's protein-synthesizing machinery. They include the ribosomal protein $\mathrm{S} 1$ and the elongation factors EF-Tu and EF-Ts (the normal function of these proteins is described in chapter 12). A hexameric protein called host factor is also required for $\mathrm{Q} \beta$ replication. The role that proteins normally involved in protein synthesis could play in RNA transcription is of considerable interest, although incompletely understood. It is discussed in section 12.10.2. EF-Tu and EF-Ts are required for replication but are only loosely bound to the complex of S1 and II. They appear to have a stabilizing role whereas $\mathrm{S} 1$ and host factor probably function in the binding of replicase to $Q \beta$ RNA.

\subsubsection{Eukaryotic RNA viruses}

\section{(a) Picornaviruses (class IV)}

These have single-stranded RNA genomes which can function as mRNAs (+ strands). The most thoroughly studied example is poliovirus, the $7.5 \mathrm{~kb}$ genome of which is a polyadenylated mRNA linked at its 5 '-terminus to a 22 amino acid peptide, VPg. The genome is translated by host ribosomes into a giant polyprotein. This is then cleaved by proteases into a number of proteins including the four viral capsid proteins, part of the replicase and a number of other products including VPg.

Polio virus RNA polymerase (replicase) has been purified from infected cells and from $E$. coli expressing the protein from recombinant plasmids. It is a $53000 \mathrm{kDa}$ protein that is unable to initiate RNA synthesis without either an oligonucleotide primer or factors produced by the host cell. The role of these factors in viral RNA replication is controversial [248] as is that of VPg ([249] and references therein).

There are two main models for the replication of the viral RNA (Fig. 9.11). In the first of these, VPg, or VPg linked to two uridine monophosphates in the form of VPg-pUpU, is postulated to prime RNA synthesis [250, 251]. Baltimore [252], suggests the uridylylated VPg hybridizes to the 3'-poly(A) tail of the $(+)$ strand RNA and is then elongated by the replicase. The (-) strand so produced is copied by the replicase after VPg-pUpU has hybridized to its two $3^{\prime}$-A residues.

A second model proposes that a hairpin 
VPg
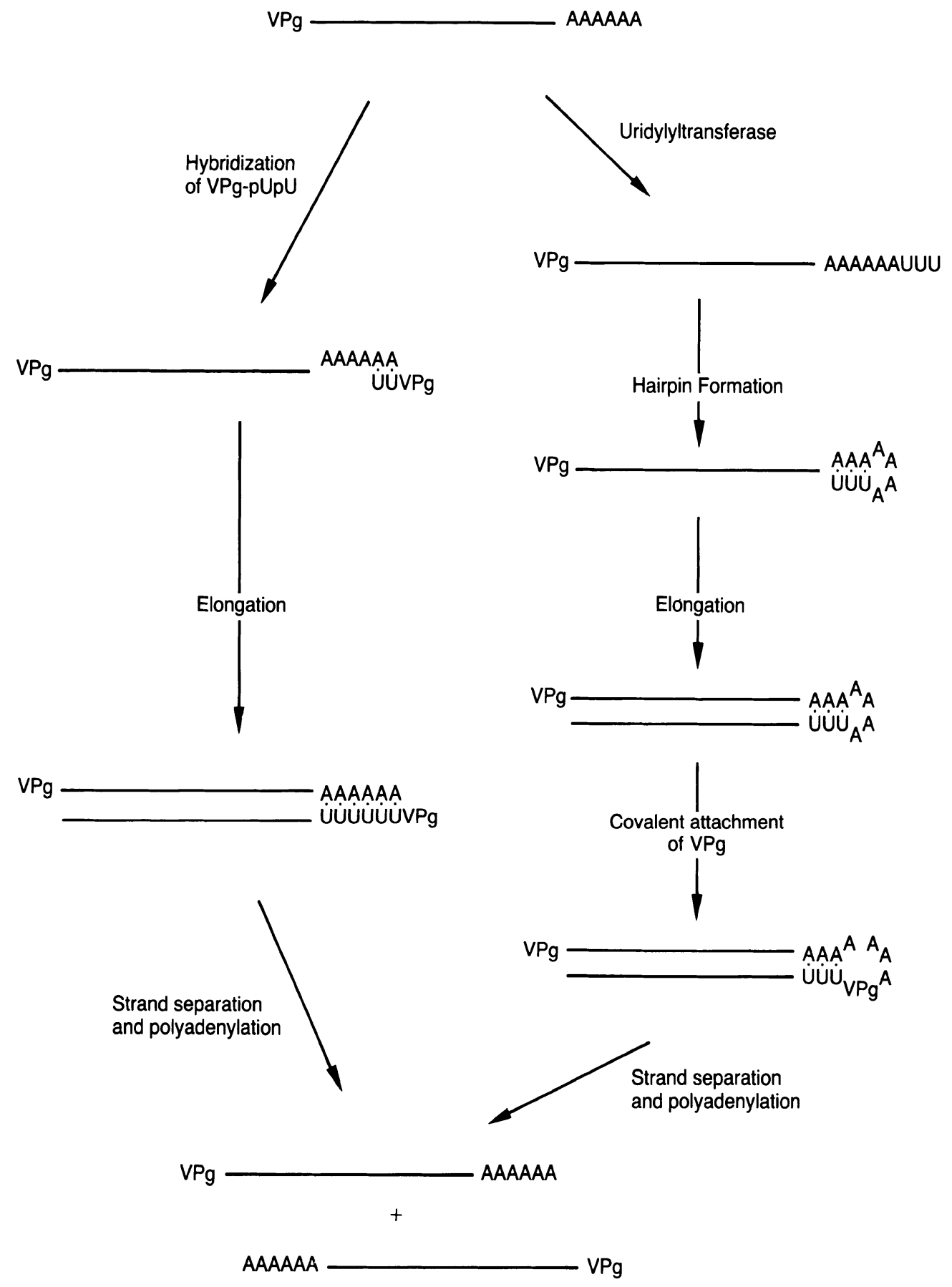

Fig. 9.11 Two models of polio virus replication. 
forms at the $3^{\prime}$-end of the polio virion RNA, possibly as a direct result of uridylylation of the poly(A) terminus by terminal uridylyltransferase. The hairpin primes the elongation of the complementary $(-)$ strand RNA. In this model (Fig. 9.11), VPg is thought to function in the trans-esterification required to break a phosphodiester bond within the hairpin. The template $(+)$ strand and the product (-) strand then separate leaving a product with VPg linked to its 5 '-terminus [249].

\section{(b) Rhabdoviruses (class V)}

Rhabdoviruses have single-stranded, (-) strand RNA genomes that cannot function as mRNAs. They must be copied into $(+)$ strands before they can be expressed. To achieve this, the infective viruses contain an RNA-dependent RNA polymerase or replicase (also known as a transcriptase). The most thoroughly studied example is vesicular stomatitis virus (VSV), the singlestranded genome of which has an $M_{\mathrm{r}}$ of $4 \times$ $10^{6}$. It is tightly associated with 1258 copies of the nucleocapsid protein $\mathrm{N}$ and this complex, together with smaller quantities of the replicase (protein $\mathrm{L}[253,254]$ ) and the phosphoprotein NS, constitutes the transcribing ribonucleoprotein complex (RNP). The replicase synthesizes five distinct species of mRNA from the RNP complex in vitro and in vivo. These include the RNP proteins $\mathrm{N}, \mathrm{L}$ and NS as well as the virion proteins $\mathrm{M}$ and $\mathrm{G}$ (in the virion, the RNP is coiled into a tight helix associated with the matrix protein $\mathrm{M}$ and the glycoprotein $\mathrm{G}$ projects through the outer lipid bilayer that is acquired from the host).

Much remains to be fully understood of the transcription and replication of VSV and other rhabdovirus (reviewed in [255]). RNA synthesis initiates at the 3 '-end of the viral RNA with the synthesis of a leader RNA

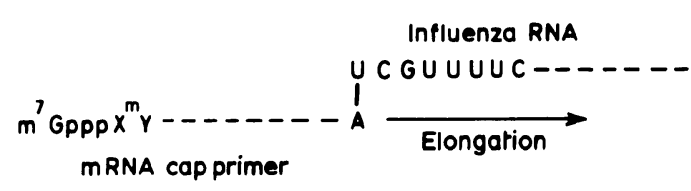

Fig. 9.12 The priming of influenza virus RNA synthesis.

but it is not clear whether subsequent transcription is continuous through the five genes or whether it results from multiple initiation events. The mRNAs synthesized in vitro are typical of those of eukaryotes in carrying a methylated 5'-cap and a $3^{\prime}$ polyadenylated tail. Virus-specific enzyme activities carry out these modifications but for the most part have not been identified with specific proteins. The replicase is also responsible for replication, namely the copying of complete $(+)$ strands into $(-)$ strands.

\section{(c) Myxovirus (class $V$ )}

These viruses have a segmented, singlestranded RNA genome in seven or more distinct non-overlapping pieces and with negative polarity. The most-studied example is influenza. The virus encodes and packages its own replicating system. However, viral mRNA synthesis also requires cellular mRNA, the 5 -terminal portions of which are used as primers. The 5'-terminal cap $\left(\mathrm{m}^{7} \mathrm{GpppXm}\right.$ - section 11.4) of cellular mRNA is cleaved by a cap-dependent viral endonuclease at a purine residue $10-13$ nucleotides downstream from the cap [256]. The resulting fragments are weakly bonded to the viral RNA segments, it is presumed by a single base pair between a $3^{\prime}$-terminal A of the primer and a $3^{\prime}-U$ of the viral RNA (Fig. 9.12). They then function as a primer for elongation by the viral transcriptase (reviewed in $[257,258]$ ). 
(d) Reoviruses (class III)

These are double-stranded RNA viruses of which human reovirus type 3 is a typical example (reviewed in [259]). The genome consists of ten segments of double-stranded RNA, each specifying a single polypeptide. Each is transcribed asymmetrically and conservatively by a virion-associated RNA polymerase into $(+)$ RNA strands. These mRNAs are capped but contain no poly(A). However, they are functional mRNAs and are translated by host cell ribosomes. In viral replication the ten $(+)$ strand mRNA molecules complex with some of the viral proteins. The (-) strand RNAs are synthesized on this complex.

\section{(e) Retroviruses (class VI)}

Retroviruses differ from other animal viruses in containing an RNA genome that replicates through a DNA intermediate that is stably inserted into the host chromosomes mutating and occasionally capturing cellular genes. The genome of the free viral particle consists of two identical single-stranded RNA chains wrapped around a core of viral protein. Each RNA chain is base paired with a host-specific tRNA molecule that functions as a primer for reverse transcriptase that copies the RNA into DNA. Reverse transcriptase and the replication of retroviruses are discussed in chapter 6 (sections 6.4 .8 and 6.14 , respectively).

The duplex DNA, that results from the replication, is stably integrated into the host chromosome (section 6.14). The encoded genes are then expressed by host cell enzymes under the direction of viral control elements. These typically include enhancers and promoters that are located mainly in the LTR and U3 regions of the viral DNA.

\section{REFERENCES}

1 Weiss, S. and Gladstone, L. (1959) J. Am. Chem. Soc., 81, 4118.

2 Chamberlin, M. J. (1976) in RNA Polymerase (eds R. Losick and M. Chamberlin), Cold Spring Harbor Laboratory, New York, p. 159.

3 Chamberlin, M. J. (1982) in The Enzymes (ed. P. Boyer), Academic Press, New York, vol. 15 , p. 61 .

4 von Hippel, P. H., Bear, D. G., Morgan, W. D. and McSwiggen, J. A. (1984) Annu. Rev. Biochem., 53, 389.

5 Miller, J. A., Serio, G. F., Howard, R. A., Bear, J. L., Evans, J. E. and Kimball, A. P. (1979) Biochim. Biophys. Acta, 579, 291.

6 Burgess, R. R., Travers, A. A., Dunn, J. J. and Bautz, E. K. (1969) Nature (London), 221, 43.

7 Zillig, W., Palm, P. and Heil, A. (1976) in RNA Polymerase (eds $\mathrm{R}$. Losick and $\mathrm{M}$. Chamberlin), Cold Spring Harbor Laboratory, New York, p. 101.

8 Krakow, J. S., Rhodes, G. and Jovin, T. M. (1976) in RNA Polymerase (eds R. Losick and M. Chamberlin), Cold Spring Harbor Laboratory, New York, p. 127.

9 Scaife, J. (1976) in RNA Polymerase (eds R. Losick and M. Chamberlin), Cold Spring Harbor Laboratory, New York, p. 207.

10 McClure, W. R. (1985) Annu. Rev. Biochem., 54, 171.

11 Berg, O. G., Winter, R. B. and von Hippel, P. H. (1981) Biochemistry, 20, 6929.

12 von Hippel, P. H., Bear, D. G., Morgan, W. D. and McSwiggen, J. A. (1984) Annu. Rev. Biochem., 53, 389.

13 Winter, R. B., Berg, O. G. and von Hippel, P. H. (1981) Biochemistry, 20, 6961.

14 Park, C. S., Wu, F. Y-H. and Wu, C-W. (1982) J. Biol. Chem., 257, 6950.

15 Hannon, R., Richards, E. G. and Gould, H. J. (1986) EMBO J., 5, 3313.

16 Berg, O. G., Winter, R. B. and von Hippel, P. H. (1982) Trends Biochem. Sci., 7, 52.

17 Ricchetti, M., Metzger, W. and Heumann, H. (1988) Proc. Natl. Acad. Sci. USA, 85, 4610 .

18 Metzger, W., Schickor, P. and Heumann, H. (1989) EMBO J., 8, 2745.

19 Rosenberg, H. and Court, D. (1979) Annu. 
Rev. Genet., 13, 319.

20 Siebenlist, U., Simpson, R. B. and Gilbert, W. (1980) Cell, 20, 269.

21 Hawley, D. K. and McClure, W. R. (1983) Nucleic Acids Res., 11, 2237.

22 Youderian, P., Bouvier, S. and Susskind, M. M. (1982) Cell, 30, 843.

23 Brunner, M and Bujard, H. (1987) EMBO J., 6, 3139.

24 O'Neil, M. C. (1989) J. Biol. Chem., 264, 5522.

25 Auble, D. T. and deHaseth, P. L. (1988) J. Mol. Biol., 202, 471.

26 Smith, G. R. (1981) Cell, 24, 599.

27 Waldberger, C., Gardella, T., Wong, R. and Suskind, M. (1990) J. Mol. Biol., 215, 267.

28 Liebig, H-D. and Rüger, W. (1989) J. Mol. Biol., 208, 517.

$29 \mathrm{Buc}, \mathrm{H}$. and McClure, W. R. (1985) Biochemistry, 24, 2712.

30 Buc, H. (1987) in Nucleic Acids and Mol. Biol. (eds Eckstein, F. and Lilley, D.) Springer, Heidelberg, vol. 1, 186.

31 Amouyal, M. and Buc, H. (1987) J. Mol. Biol., 195, 795.

32 Buc, H., Amouyal, M., Buckle, M., Herbert, M., Kolb, A. et al. (1987) in RNA Polymerase and the Regulation of Transcription (eds W. S. Retznikof et al.), Elsevier, Amsterdam, p. 115.

33 Krakow, J. S., Rhodes, G. and Jovin, T. M. (1976) in RNA Polymerase (eds R. Losick and M. Chamberlin), Cold Spring Harbor Laboratory, New York, p. 127.

34 Krummel, B. and Chamberlin, M. J. (1989) Biochemistry, 28, 7829.

35 Stackhouse, T. M., Telusnitsky, A. P. and Meares, C. F. (1989) Biochemistry, 28, 7781.

36 Shimamoto, N., Kamigochi, T. and Utiyama, H. (1986) J. Biol. Chem., 261, 11859.

37 Liu, L. F. and Wang, J. C. (1987) Proc. Natl. Acad. Sci. USA, 84, 7024.

$38 \mathrm{Wu}, \mathrm{H}-\mathrm{Y}$., Shyy, S., Wang, J. C. and Liu, L. F. (1988) Cell, 53, 433.

39 Giaever, G. N. and Wang, J. C. (1988) Cell, 55, 849.

40 Tsao, Y-P., Wu, H-Y. and Liu, L. F. (1989) Cell, 56, 111.

41 Chamberlin, M. J., Nierman, W. C., Wiggs, J. and Neff, N. (1979) J. Biol. Chem., 254, 10061.
42 Kassavetis, G. A. and Chamberlin, M. J. (1981) J. Biol. Chem., 256, 2777.

43 Gamper, H. B. and Hearst, J. E. (1982) Cell, 29, 81.

44 Morgan, W. D., Bear, D. G. and von Hippel, P. H. (1983) J. Biol. Chem., 258, 9565.

45 Chamberiin, M., Kingston, R., Gilman, M., Wiggs, J. and de Vera, A. (1983) Methods Enzymol., 101, 540.

46 Adhya, S. and Gottesman, M. (1978) Annu. Rev. Biochem., 47, 967.

47 Bear, D. G. and Peabody, D. S. (1988) Trends. Biochem. Sci., 13, 343.

48 Richardson, J. P. (1991) Cell, 64, 1047.

49 Farnham, P. J. and Platt., T. (1981) Nucleic Acids Res., 9, 563.

50 Bertrand, K., Korn, L., Lee, F. and Yanofsky, C. (1977) J. Mol. Biol., 117, 227.

51 Martin. F. and Tinoco, I. (1980) Nucleic Acids Res., 8, 2295.

52 O'Hare, K. M. O. and Hayward, R. S. (1981) Nucleic Acids Res., 9, 4689.

53 Arndt, K. M. and Chamberlin, M. J. (1988) J. Mol. Biol., 202, 271.

54 Arndt, K. M. and Chamberlin, M. J. (1990) J. Mol. Biol., 213, 79.

55 Goliger, J. A., Yang, X., Guo, H-C. and Roberts, J. W. (1989) J. Mol. Biol., 205, 331.

56 Telisnitsky, A. and Chamberlin, M. J. (1989) J. Mol. Biol., 205, 315.

57 Roberts, J. W. (1969) Nature (London), 224, 1168.

58 Dombroski, A. J. and Platt, T. (1988) Proc. Natl. Acad. Sci. USA, 85, 2538.

59 McSwiggen, J. A., Bear, D. G. and von Hippel, P. H. (1988) J. Mol. Biol., 199, 609.

60 Bear, D. G., Hicks, P. S., Escudero, K. W., Andrews, C. L., McSwiggen, J. A. et al. (1988) J. Mol. Biol., 199, 623.

61 Dombroski, A. J., LaDine, J., Cross, R. L. and Platt, T. (1988) J. Biol. Chem., 263, 18810.

62 Brennan, C. A., Dombroski, A. J. and Platt, T. (1987) Cell, 48, 945.

63 Dombroski, A. J., Brennan, C. A., Spear, P. and Platt, T. (1988) J. Biol. Chem., 263, 18802.

64 Brennan, C. A., Steinmetz, E. J., Spear, P. and Platt, T. (1990) J. Biol. Chem., 265, 5440 .

65 Morgan, W. D., Bear. D. G. and von 
Hippel, P. H. (1983) J. Biol. Chem., 258, 9565.

66 Faus, I. and Richardson, J. P. (1990) J. Mol. Biol., 212, 53.

67 Morgan, W. D., Bear, D. G. and von Hippel, P. H. (1984) J. Biol. Chem., 259, 8664.

68 Morgan, W. D., Bear, D. G., Litchman, B. L. and von Hippel, P. H. (1985) Nucleic Acids Res., 13, 3739.

69 Albrechtsen, B., Squires, C. L., Li, S. and Squires, C. (1990) J. Mol. Biol., 213, 123.

70 Sentenac, A. (1985) Crit. Rev. Biochem., $18,31$.

71 Sawadogo, M. and Sentenac, A. (1990) Annu. Rev. Biochem., 59, 711.

72 Woychick, N. A. and Young, R. A. (1990) Trends Bichem Sci., 15, 347.

73 Geiduschek, E. P. and Tocchini-Valentini, G. P. (1988) Annu. Rev. Biochem., 57, 873.

74 Sollner-Webb, B. and Mougey, E. B. (1991) Trends Biochem. Sci., 16, 58.

75 Anderson, J. A., Juntz, G. P. P., Evans, H. H. and Swift, T. J. (1971) Biochemistry, 10, 4368.

76 De Mercoyrol, L., Job, C. and Job, D. (1989) Biochem. J., 258, 165.

77 Himmelfarb, H. J., Simpson, E. M. and Friesen, J.'D. (1987) Mol. Cell. Biol., 7, 2155.

78 Lewis, M. K. and Burgess, R. R. (1982) in The Enzymes (ed. P. Boyer), Academic Press, New York, vol. 15, p. 109.

79 Kolodziej, P. A., Woychick, N. A., Lao, S. M. and Young, R. A. (1990) Mol. Cell. Biol., 10, 1915.

80 Martin, C., Okamura, S. and Young, R. (1990) Mol. Cell. Biol., 10, 1908.

81 Corden, J. L. (1990) Trends. Biochem. Sci., 15, 383

82 Laybourn, P. L. and Dahmus, M. E. (1990) J. Biol. Chem., 265, 13165.

83 Allison, L. A. and Ingles, C. J. (1989) Proc. Natl. Acad. Sci. USA, 86, 2794.

84 Kolodkiej, P. and Young, R. A. (1989) Mol. Cell. Biol., 9, 5387.

85 Riva, M., Christophe, C., Sentenac, A., Grachev, M. A., Mustaev, A. A. et al. (1990) J. Biol. Chem., 265, 16498.

86 Woychick, N. A., Liao, S. M., Kolodziej, P. A. and Young, R. A. (1990) Genes Devel. , 4, 313.

87 Wu, G-J. (1978) Proc. Natl. Acad. Sci. USA, 75, 2175 .
88 Weil, P. A., Segall, J., Harris, B., Ng, S. Y. and Roeder, R. G. (1979) J. Biol. Chem., 254, 6163.

89 Birkenmeier, E. H., Brown, D. D. and Jordan, E. (1978) Cell, 15, 1077.

90 Weil, P. A., Luse, D. S., Segall, J. and Roeder, R. G. (1979) Cell, 18, 469.

91 Wasylyk, B., Kedinger, C., Corden, J., Brison, O. and Chambon. P. (1980) Nature (London), 285, 367.

92 Grummt, I. (1981) Proc. Natl. Acad. Sci. USA, 78, 727.

93 Grummt, I., Roth, E. and Paule, M. R. (1982) Nature (London), 296, 173.

94 Brown, D. P. and Gurdon, J. B. (1977) Proc. Natl. Acad. Sci. USA, 74, 2064.

95 Pellicer, A. , Robins, D., Wold, B., Sweet, R., Jackson, J. et al. (1980) Science, 209, 1414.

96 Hamer, D. and Leder, P. (1979) Cell, 21, 697.

97 Mellon, P., Parker, V., Gluzrnan, Y. and Manniatis, T. (1981) Cell, 27, 279.

98 Goldberg, M. (1979) Ph.D. thesis, Stanford University, California.

99 Brady, J., Radonovitch, M., Vodkin, M., Natarajan, V., Thoren, M. et al. (1982) Cell, 31, 625 .

100 Skuzeski, J. M., Lund, E., Murphy, J. T., Steinberg, T. H., Bargess, R. R. and Dahlberg, J. E. (1984) J. Biol. Chem., 259, 8345.

101 Dynan, W. S. (1988) Trends Genet., 2, 196.

102 McKnight, S. L. (1982) Cell, 31, 355.

103 Everett, R. D., Baly, D. and Chambon, P. (1983) Nucleic Acids Res., 11, 2447.

104 Dierks, P., van Ooyen, A., Cochran, M. D., Dobkin, C., Reiser, J. and Weissmann, C. (1983) Cell, 32, 695.

105 Conaway, J. W., Reines, D. and Conaway, R. C. (1990) J. Biol. Chem., 265, 7552.

106 Conaway, R. C. and Conaway, J. W. (1990) J. Biol. Chem., 265, 7559 .

107 Kitajima, S., Kawaguchi, T., Yasukochi, Y. and Weissman, S. M. (1989) Proc. Natl. Acad. Sci. USA, 86, 6106.

108 Kitajima, S., Tanaka, Y., Kawaguchi, T., Nagaoka, T., Sherman, M. et al. (1990) Nucleic Acids Res., 18, 4843.

109 Sopta, M., Burton, Z. F. and Greenblatt, J. (1989) Nature (London), 341, 410.

110 Flores, O., Ha, I. and Reinberg, D. (1990) J. Biol. Chem, 265, 5629.

111 Horikoshi, M., Yamamoto, T., Ohkuma, 
Y., Weil, P. A. and Roeder, R. G. (1990) Cell, 61, 1171.

112 Hahn, S., Buratowski, S., Sharp, P. A. and Guarente, L. (1989) Proc. Natl. Acad. Sci. $U S A, 86,5718$.

113 Lewin, B. (1990) Cell, 61, 1161.

114 Van Dyke, M. W., Roeder, R. G. and Sawadogo, M. (1988) Science, 241, 1335.

115 Hoey, T., Dynlacht, B. D., Peterson, M. G., Pugh, B. F. and Tjian, R. (1990) Cell, 61, 1179.

116 Hoffmann, A., Sinn, E., Yamamoto, T., Wang, J., Roy, A. et al. (1990) Nature (London), 346, 387.

117 Pugh, B. F. and Tjian, R. (1990) Cell, 61, 1187.

118 Stringer, K. F., Ingles, C. J. and Greenblatt, J. (1990) Nature (London), 345, 783.

119 Horikoshi, M., Carey, M. F., Kakidani, H. and Roeder, R. G. (1988) Cell, 54, 665.

120 Sollner-Webb, B. (1988) Cell, 52, 153.

121 Palmer, J. M. and Folk, W. M. (1990) Trends Biochem. Sci., 15, 300.

122 Sakonja, S., Bogenhagen, D. F. and Brown, D. D. (1980) Cell, 19, 13.

123 Bogenhagen, D. F., Sakonju, S. and Brown, D. D. (1980) Cell, 19, 27.

124 Cozzarelli, N. R., Gerrard, S. P., Schlissel, M., Brown, D. D. and Bogenhagen, D. F. (1983) Cell, 34, 829.

125 Engelke, D. R., Ng, S-Y., Shastry, B. S. and Roeder, R. G. (1980) Cell, 19, 717.

126 Bogenhagen, D. F. (1985) J. Biol. Chem., 260, 6466 .

127 Windsor, W. T., Lee, T. C., Daly, T. J. and Wu, C. W. (1988) J. Biol. Chem., 263, 10272.

128 Bieker, J. J., Martin, P. L. and Roeder, R. G. (1985) Cell, 40, 119.

129 Hall, B. D., Clarkson, S. G. and TocciniValentini, G. (1982) Cell, 29, 3.

130 Gabrielsen, O. S., Marzouki, N., Ruet, A., Sentenac, A. and Frogageot, P. (1989) J. Biol. Chem., 264, 7505.

131 Schultz, P., Marzouki, N., Marck, C., Ruet, . A., Oudet, P. et al. (1989) EMBO J., 8, 3815.

132 Johnson, D. L. and Wilson, S. L. (1989) Mol. Cell. Biol., 9, 2018.

133 Kassavetis, G. A., Braun, B. R., Nguyen, L. H. and Geiduschek, E. P. (1990) Cell, 60, 235.

134 Huibregtse, J. M. and Engelke, D. R. (1989) Mol. Cell. Biol., 9, 3244.
135 Tyler, B. M. (1987) J. Mol. Biol., 196, 801.

136 Murphy, S., Moorefield, B. and Pieler, T. (1989) Trends Genet., 5, 122.

137 Moenne, A., Camier, S., Anderson, G., Margottin, F., Beggs, J. and Sentenac, A. (1990) EMBO J., 9, 271.

138 Waibel, F. and Filipowicz, W. (1990) Nature (London), 346, 199.

139 Kleinert, H., Bredow, S. and Benecke, B. L. (1990) EMBO J., 9, 711.

140 Murphy, S., Peirani, A., Scheidereit, C., Melli, M. and Roeder, R. G. (1989) Cell, 59, 1071.

141 Wolffe, A. P. and Brown, D. D. (1988) Science, 241, 1626.

142 Blanco, J., Milstein, L., Razik, M. A., Dilworth, S., Cote, C. and Gottesfeld, J. (1989) Genes Devel., 3, 1602.

143 Moss, T. (1982) Cell, 30, 835.

144 Grummt, I., Roth, E. and Paule, M. (1982) Nature (London), 296, 173.

145 Onishi, T., Berglund, C. and Reeder, R. H. (1984) Proc. Natl. Acad. Sci. USA, 81, 484.

146 Haltina, M. M., Smale, S. T. and Tjian, R. (1986) Mol. Cell. Biol., 6, 227.

147 Jones, M. H., Learned, R. M. and Tjian, R. (1988) Proc. Natl. Acad Sci. USA., 85, 669.

148 Cassidy, B., Hagland, R. and Rothblum, L. (1987) Biochim. Biophys. Acta, 909, 133.

149 Yang-Yen, H-F. and Rothblum, L. (1988) Mol. Cell. Biol., 8, 3406.

150 Henderson, S. L. and Sollner-Webb, B. (1990) Mol. Cell. Biol., 10, 4970.

151 Miller, J. R., Hayward, D. C. and Glover, D. M. (1983) Nucleic Acids Res., 11, 11.

152 Simeone, A., La Volpe, A. and Boncinelli, E. (1985) Nucleic Acids Res., 13, 1189.

153 Labhart, P. and Reeder, R. H. (1984) Cell, $37,285$.

154 Reeder, R. H. (1984) Cell, 38, 349.

155 Pikaard, C. S., Pape, L. K., Henderson, S. L., Ryan, K., Paalman, M. H. et al. (1990) Mol. Cell. Biol., 10, 4816.

156 Smith, S. D., Oriahi, E., Yang-Yen, H-F., Xie, W., Chen, C. et al. (1990) Nucleic Acids Res., 18, 1677.

157 Moss, T. (1983) Nature (London), 302, 223.

158 Bell, S. P., Learned, R. M., Jantzen, H-M. and Tjian, R. (1988) Science, 241, 1192.

159 Pikaard, C. S., Smith, S. D., Reeder, R. H. and Rothblum, L. (1990) Mol. Cell. Biol., 10, 3810 .

160 Pikaard, C. S., McStay, B., Schultz, M. C., Bell, S. P. and Reeder, R. H. (1989) Genes 
Devel., 3, 1779.

161 Learned, R. M., Cordes, S. and Tjian, R. (1985) Mol. Cell. Biol., 5, 1358.

162 Bell, S. P., Jantzen, H-M. and Tjian, R. (1990) Genes Devel., 4, 943.

163 Learned, R. M., Learned, T. K., Haltiner, M. M. and Tjian, R. (1986) Cell, 45, 847.

164 Bell, S. P., Learned, R. M., Jantzen, H-M. and Tjian, R. (1988) Science, 241, 1192.

165 Bell, S. P., Pikaard, C. S., Reeder, R. H. and Tjian, R. (1989) Cell, 59, 489.

166 Tower, J. and Solner-Webb, B. (1987) Cell, 50, 873.

167 Schnapp, A., Pfleiderer, C., Rosenbauer, H. and Grummt, I. (1990) EMBO J., 9, 2857.

168 Mahajan, P. B. and Thompson, E. A. (1990) J. Biol. Chem., 265, 16225.

169 Mahajan, P. B., Gokal, P. B. and Thompson, E. A. (1990) J. Biol. Chem., 265, 16244.

170 Baker, S. M. and Platt, T. (1986) Cell, 47, 839.

171 Labhart, P. and Reeder, R. H. (1989) Proc. Natl. Acad. Sci. USA, 86, 3155.

172 Proudfoot, N. J. and Whitelaw, E. (1988) in Frontiers in Molecular Biology, IRL Press, Oxford, p. 97.

173 Citron, B., Falck-Pederson, E., SaldittGeorgieff, M. and Darnell, J. E. (1984) Nucleic Acids Res., 12, 8723.

174 Haggenbüchle, O., Welleur, P. K., Cribbs, D. L. and Schibler, U. (1984) Cell, 38, 737.

175 Proudfoot, N. J. (1989) Trends Biochem. Sci., 14, 105.

176 Whitelaw, E. and Proudfoot, N. J. (1986) EMBO J., 5, 2915.

177 Logan, J., Falck-Pederson, E., Darnell, J. E. and Shenk, T. (1987) Proc. Natl. Acad. Sci. USA, 84, 8306.

178 Connelly, S. and Manley, J. L. (1988) Genes Devel., $2,440$.

179 Lanoix, J. and Acheson, N. H. (1988) EMBO J., 7, 2515.

180 Kunkel, G. R. and Pedersen, T. (1985) Mol. Cell. Biol., 5, 2332.

181 Ciliberto, G., Dathan, N., Frank, R., Philipson, L. and Mattaj, I. W. (1986) EMBO J., 5, 2931.

182 Hernandez, N. and Weiner, A. M. (1986) Cell, 47, 249.

183 Briggs, D., Jackson, D., Whitelaw, E. and Proudfoot, N. J. (1989) Nucleic Acids Res., 17, 8061 .
184 Bogenhagen, D. F. and Brown, D. D. (1981) Cell, 24, 261.

185 Koski, R., Clarkson, S. G., Kurjan, J., Hall, B. D. and Smith, M. (1980) Cell, 22, 415.

186 Traboni, C., Ciliberto, G. and Cortese, R. (1984) Cell, 36, 179.

187 Gottesfeld, J. M., Andrews, D. L. and Hoch, S. O. (1984) Nucleic Acids Res., 12, 3185.

188 Gottlieb, E. and Steitz, J. A. (1987) in RNA Polymerase and the Regulation of Transcription (eds W. S. Reznikoff et al.), Elsevier, New York, p. 465.

189 Stefano, J. E. (1984) Cell, 36, 145.

190 Gottlieb, E. and Steitz, J. A. (1989) EMBO $J ., 8,851$.

191 Bachmann, M., Pfiefer, K., Schröder, H. C. and Müller, W. (1990) Cell, 60, 85.

192 Labhart, P. and Reeder, R. H. (1986) Cell, 45, 431 .

193 Labhart, P and Reeder, R. H. (1987) Mol. Cell. Biol., 7, 1900.

194 Labhart, P. and Reeder, R. H. (1990) Genes Devel., 4, 269.

195 McStay, B. and Reeder, R. H. (1990) Genes Devel., 4, 1240.

196 McStay, B. and Reeder, R. H. (1990) Mol. Cell. Biol., 10, 2793.

197 Grummt, I., Maier, U., Öhrlein, A., Hassouna, N. and Bachellerie, J-P. (1985) Cell, 43, 801.

198 Grummt, I., Rosenbauer, H., Niedermyer, I., Maier, U. and Örhlein, A. (1986) Cell, 45, 837.

199 Kuhn, A. and Grummt, I. (1989) Genes Devel., 3, 224.

200 Bartsch, I., Schoneberg, C. and Grummt, I. (1988) Mol. Cell. Biol., 8, 3891.

201 Pfiederer, C., Smid, A., Bartsch, I. and Grummt, I. (1990) Nucleic Acids Res., 18, 4727.

202 Cook, P. R. (1989) Eur. J. Biochem., 185, 487.

203 Roberge, M., Duhmas, M. E. and Bradbury, E. M. (1988) J. Mol. Biol., 201, 545.

204 Robinson, S. I., Small, D., Idzerda. R., McKnight, G. S. and Vogelstein, B. (1983) Nucleic Acids Res., 11, 5113.

205 Ciejek, E. M., Tsai, M-J. and O'Malley, B. W. (1983) Nature (London), 306, 607.

206 Hentzen, P. C., Rho, J. H. and Bekhor, I. (1984) Proc. Natl. Acad. Sci. USA, 81, 304.

207 Kirov, N., Djondjurov, L. and Roumen. T. (1984) J. Mol. Biol., 180, 601. 
208 Jost, J-P. and Seldran, M. (1984) EMBO J., 3, 2005.

209 Mirkovitch, J., Mirault, M-E. and Laemmli, U. K. (1984) Cell, 39, 223.

210 Jackson, D. A. and Cook, P. R. (1985) EMBO J., 4, 919.

211 Jackson, D. A., Yuan, J. and Cook, P. R. (1988) J. Cell. Sci., 90, 365.

212 Levy-Wilson, B. and Fortier, C. (1989) J. Biol. Chem., 264, 21196.

213 Strätling, W. H., Dölle, A. and Sippel, A. E. (1986) Biochemistry, 25, 495.

214 Phi Van, L. and Stätling, W. H. (1988) EMBO J., 7, 655.

215 Jarman, A. P. and Higgs, D. R. (1988) EMBO J., 7, 3337.

216 Cockerill, P. N., Yuen, M-H. and Garrard, W. T. (1987) J. Biol. Chem., 262, 5394.

217 Steif, A., Winter, D. M., Strätling, W. H. and Sippel, A. E. (1989) Nature (London), 341, 343.

218 Kuo, M. T. (1982) J. Cell. Biol., 93, 278.

219 Schinkel, A. H. and Tabak, H. F. (1989) Trends Genet., 5, 149.

220 Fisher, R. P., Topper, J. N. and Clayton, D. A. (1987) Cell, 50, 247.

221 Chang, D. D., Fisher, R. P. and Clayton, D. A. (1987) Biochim. Biophys. Acta, 909, 85.

222 Kelly, J. L. and Lehman, I. R. (1986) J. Biol. Chem., 261, 10340.

223 Schinkel, A. H., Groot Koerkamp, M. and Tabak, H. F. (1988) EMBO J., 7, 3255.

224 Kubelik, A. R., Kennel, J. C., Akins, R. A. and Lambowitz, A. M. (1990) J. Biol. Chem., 265, 4515.

225 Levings, C. S. and Brown, G. G. (1989) Cell, 56, 171.

226 Mullet, J. E. (1988) Annu. Rev. Plant Physiol., 39, 475.

227 Gruissem, W. (1989) in The Biochemistry of Plants: a Comprehensive Treatise, vol. 15, p. 151.

228 Gruissem, W. (1989) Cell, 56, 161.

229 Reiss, T. and Link, G. (1985) Eur. J. Biochem., 148, 207.

230 Narita, J. O., Rushlow, K. E. and Hallick, R. B. (1985) J. Biol. Chem., 260, 11194.

231 Orozco, E. M., Mullet, J. E. and Chua, N. H. (1985) Nucleic Acids Res., 13, 1283.

232 Ishihama, A. and Nagata, K. (1988) Crit. Rev. Biochem., 23, 27.

233 Studier, F. W. and Dunn, J. J. (1983) Cold Spring Harbor Symp. Quant. Biol., 47, 999.
234 Davanloo, P., Rosenberg, A. H., Dunn, J. J. and Studier, F. W. (1984) Proc. Natl. Acad. Sci. USA, 81, 2035.

235 Gunderson, S. I., Chapman, K. A. and Burgess, R. R. (1987) Biochemistry, 26, 1539.

236 Chamberlin, M. and Ryan, T. (1982) in The Enzymes (ed. P. Boyer), Academic Press, New York, vol. 15, p. 87.

237 Klement, J. F., Moorefield, M. B., Jorgenson, E., Brown, J. E., Risman, S. et al. (1990) J. Mol. Biol., 215, 21.

238 Buer, R., Bankier, A. T., Biggin, M. D., Deininger, P. L., Farell, P. J. et al. (1984) Nature (London), 310, 207.

239 Arrand, J. R. and Rymo, L. (1982) J. Virol., 41, 376.

240 Moss, B. (1990) Annu. Rev. Biochem., 59, 661.

241 Traktman, P. (1990) Cell, 62, 621.

242 Nevins, J. R. and Joklik, W. K. (1977) J. Biol. Chem., 252, 6930.

243 Broyles, S. S., Yuen, L., Shuman, S. and Moss, B. (1988) J. Biol. Chem., 263, 10754.

244 Shuman, S. (1990) J. Biol Chem., 265, 11960.

245 Shuman, S and Morham, S. G. (1990) J. Biol. Chem., 265, 11967.

246 Blumenthal, T. (1982) in The Enzymes (ed. P. D. Boyer), Academic Press, New York, vol. 15 , p. 267.

247 Mills, D. R., Priano, C., DiMauro, P. and Binderow, B. D. (1989) J. Mol. Biol., 205, 751.

248 Paul, A. V., Yang, C. F., Jang, S-K., Kuhn, R. J., Tada, H. et al. (1987) Cold Spring Harbor Symp. Quant. Biol., 52, 343.

249 Tobin, G. J., Young, D. C. and Flanegan, J. B. (1989) Cell, 59, 511.

250 Crawford, N. M. and Baltimore, D. (1983) Proc. Natl. Acad. Sci. USA, 80, 7452.

251 Takeda, N., Yang, C. F., Kuhn, R. J. and Wimmer, E. (1987) Virus Res., 8, 193.

252 Baltimore, D. (1984) in The Microbe 1984, Society for General Biology Symposium, 36, part 1 (eds B. W. J. Mahy and J. R. Pattison), Cambridge University Press, Cambridge, p. 109.

253 Ongradi, J., Cunningham, C. and Szilagyi, J. F. (1985) J. Gen. Virol., 66, 1011.

$254 \mathrm{De}$, B. P. and Banerjee, A. K. (1985) Biochem. Biophys. Res. Commun., 126, 40.

255 Banerjee, A. K. (1987) Miocrobiol. Rev., 51, 66 . 
256 Plotch, S., Bouloy, M., Ulmanen, I. and Krug, R. M. (1981) Cell, 23, 847.

257 Krug, R. M. (1981) Curr. Top. Microbiol. Immunol., 93, 125.

258 Krug, R. M. (1985) Cell, 41, 651.

259 Wagner, R. R. (1975) in Comprehensive Virology (eds H. Fraenkel-Conrat and R. R. Wagner), Plenum Press, New York, vol. 4, p. 1.

260 Alifano, P., Rivellini, F., Limauro, D., Bruni, C. B. and Carlomagno, S. (1991) Cell, 64, 553.

261 Zhang, J. and Corden, J. L. (1991) J. Biol. Chem., 266, 2297.

262 Sumimoto, H., Ohkuma, Y., Yamamoto, T., Horikoshi, M. and Roeder, R. G. (1990) Proc. Natl. Acad. Sci. USA, 87, 9158.

263 Johnson, P. F. and McKnight, S. (1989)
Annu. Rev. Biochem., 58, 799.

264 Horikoshi, M., Hai, T., Lin, Y-S., Green, M. R. and Roeder, R. G. (1988) Cell, 54, 1033.

265 Reeder, R. H. (1990) Trends Genet., 6, 390.

266 Pikaard, C. S., McStay, B., Schultz, M. C., Bell, S. P. and Reeder, R. H. (1989) Genes Devel., 3, 1779.

267 Reeder, R. H. (1989) Curr. Opinion Cell Biol., 1, 466.

268 Chodchoy, N., Pandey, R. N. and Marzluff, W. F. (1991) Mol. Cell. Biol., 11, 497.

269 Muller, D. K., Martin, C. T. and Coleman, J. E. (1989) Biochemistry, 28, 3306.

270 Lescure, A., Carbon, P. and Krol, A. (1991) Nucleic Acids Res., 19, 435.

271 Platt, T. (1981) Cell, 24, 10. 